\title{
Panorama general de las desigualdades de género en la economía salvadoreña 1
}

Edgar Lara López²

Recibido en Mayo 2012, aprobado en Septiembre 2012

\begin{abstract}
Resumen
El presente artículo tiene como propósito hacer una aproximación al estado de la igualdad de género en la economía. La concepción de género se entiende a partir de dos dimensiones: la primera, para entender las relaciones de poder y, la segunda, para comprender que el sujeto en la economía transciende la concepción binaria del mismo.
\end{abstract}

Palabras claves

Género, sujeto económico, desigualdad, relaciones de poder, marco legal

\section{Abstract}

This paper aims to approach the state of gender equality in the economy. The concept of gender is understood from two dimensions: first, to understand the relations of power: and second, to understand that subject in economy transcends beyond the binary conception of him or her.

Keywords

Gender, economic subject, inequality, power relations, legal framework

\section{Introducción}

Con la ratificación en agosto de 1981 de la Convención sobre la Eliminación de todas las Formas de Discriminación contra la Mujer -CEDAW-, El Salvador asume un compromiso importante en cuanto a disponer de medios y políticas orientados

1. El artículo ha sido elaborado en calidad de becario del programa de MAEC-AECID del Ministerio de Asuntos Exteriores y de Cooperación y la Agencia Española de Cooperación Internacional para el Desarrollo

2.Profesor investigador, radicado en España. E-mail: edgarl_lo@hotmail.com 
a eliminar la discriminación contra la mujer; por otra parte, se adhirió a la Declaración y Plataforma de Acción de Beijing de la Cuarta Conferencia Mundial sobre la Mujer -DPAB- de mayo de 1995, en donde los países se comprometen a promover la potencialidad y adelanto de las mujeres. La declaración y plataforma dio lugar a la creación en 1991, del Instituto Salvadoreño para el Desarrollo de la Mujer -ISDEMU-, instancia del Estado responsable de desarrollar y ejecutar la Política Nacional de la Mujer. Estos acontecimientos -junto con otra serie de convenciones regionales- pueden constituirse como la primera ola de acciones en materia de política de igualdad del Estado salvadoreño.

Como producto de esta primera ola, en el país se han observado aspectos positivos en cuanto al progreso de las mujeres y la igualdad de género y entre algunos de ellos se destaca: Ley Contra la Violencia Intrafamiliar, las reformas al Código Penal en cuanto a acoso sexual y la trata de personas y el programa de transferencias condicionadas - Red Solidaria-, entre otras; no obstante, por el lado negativo se destaca la resistencia del Estado a ratificar el protocolo facultativo de la CEDAW, así como el retroceso en materia de legislación sobre el aborto.

La segunda ola de acciones importantes para la igualdad se ubica entre 2009 y 2011. Durante estos años, el Estado ha realizado esfuerzos importantes para la igualdad y el progreso de las mujeres como la nueva Política Nacional de las Mujeres, la Ley de Igualdad, Equidad y Erradicación de la Discriminación contra las Mujeres, la Ley Especial Integral para una Vida Libre de Violencia, el programa Ciudad Mujer y la continuidad del programa de transferencias condicionadas -Comunidades solidarias-.

Una parte importante de las acciones tiene intervenciones en el ámbito económico debido a que muchas de las desigualdades de género se producen en el mercado de trabajo o se derivan de políticas económicas sesgadas; en este sentido, el presente artículo tiene como propósito hacer una aproximación sobre el estado de la igualdad de género en la economía, para ello se ha estructurado en tres partes: la primera, expone una noción de género para estudiar la economía desde esta perspectiva; la segunda, desarrolla una descripción de la dimensión económica de las principales acciones de la segunda ola, así como un breve análisis interpretativo del género en el documento directriz de la política pública; y la tercera, haciendo uso de una serie de indicadores pretende determinar la situación de hombres y mujeres en diferentes componentes del mercado de trabajo.

Por último, se desarrollan algunas consideraciones finales que se derivan de cada una de las partes y que pretenden indicar algunos elementos o categorías a ser consideradas en próximos análisis sobre género y economía: la ruptura del binarismo de género -y del sujeto económico-en la economía, la matriz 
de inteligibilidad heterosexual como medio de reglamentación propia de la economía del sujeto económico y la aplicación de las tres dimensiones de la justicia a la economía.

\section{La noción de género para la economía}

Como punto de partida es importante hacer una breve reflexión sobre qué definición de la categoría género podría ser la más apropiada para el análisis de la economía o del mercado de trabajo, así como para las relaciones entre y al interior de los agentes económicos. $Y$ es que el género juega un papel importante para entender la orientación y gestión de la política económica, el estilo de inserción laboral de las personas y el acceso a los recursos o medios de producción; constituye un elemento valioso para estudiar, cuestionar, deconstruir y rehacer la posición que cada persona según su género ocupa en la vida social, familiar, económica y política.

El concepto de género está en constante evolución, sin embargo, el rasgo común en todas las definiciones es el orden sociocultural que define lo masculino y femenino. Podría decirse que una de las primeras nociones del concepto género se identifica en el siglo XVII en los aportes desarrollados por el escritor francés Poulain de la Barre, que expone que las desigualdades presentes entre hombres y mujeres están ligadas a factores culturales y no como producto de la naturaleza; en el siglo XX los aportes de la filósofa Simone de Beauvoir y la antropóloga Margaret Mead fueron determinantes para el surgimiento de género como categoría de análisis; así por ejemplo Beauvoir en su obra Segundo Sexo afirma que "Una no nace, sino que se hace mujer", afirmación que se encuentra interiorizada en la categoría género (Martín, 2006); Marta Lamas (2002) indica que en los años setenta el uso de la categoría género fue impulsado por el feminismo académico anglosajón con el propósito de diferenciar los aspectos socioculturales de los biológicos en la caracterización y representación de las personas, especialmente de mujeres y hombres.

De las múltiples definiciones de género que se conocen se deriva que este se refiere a las características socialmente construidas sobre la base de la diferencia sexual-biológica, por lo tanto sexo y género no son sinónimos. El sexo se entiende como "las características anatómicas de los cuerpos, incluida la genitalidad, así como las características morfológicas del aparato reproductor y aspectos tales como las diferencias hormonales y cromosómatica" (Martín, 2006). Así podría decirse que el sexo tiene que ver con la naturaleza, está determinado biológicamente, dado por los genes y se refiere a las diferencias biológicas entre hombre y mujer; en tanto que el género, está vinculado a la cultura, es culturalmente modificable, adquirido mediante procesos de socialización y señala las diferencia sociales entre mujer y hombre. 
Desde la economía feminista se puede decir que la categoría género ha sido determinante para cuestionar la neutralidad de la política económica, comprender que las desigualdades de género a nivel micro y meso tienen repercusiones a nivel macroeconómico, que la vinculación e inserción de hombres y mujeres en la economía no se realiza en iguales condiciones, que las política de igualdad tienden a ser más efectivas si existen marcos macroeconómicos adecuados, redefinir el marco conceptual de la economía, reinterpretar el mercado de trabajo, proponer estrategias de desarrollo inclusivas (Çagatay, 2004; Gálvez, 2010; Espino, 2010; Badgett, 1999; Carrasco 2009). En suma, ha demostrado que esta disciplina no está exenta de analizarse desde dicha categoría, pero cuál podría ser esa definición de género que nos permita hacer una mejor interpretación de la economía y del sujeto económico.

Si la economía estudia la organización individual y colectiva de las personas para la consecución del bienestar material, dentro de esta se establecen relaciones de poder no sólo de clases sociales, sino también basadas en la diferencia sexual y de género; asimismo dicha organización incorpora un conjunto de aspectos normativos e institucionales que regulan las relaciones y comportamientos. Cuando hablamos de economía hacemos referencia a un sujeto económico determinado, que tiene una forma de actuación, que cuenta con las instituciones que lo respaldan y condicionan, que se inserta y/o se hace dentro de una estructura social definida; si el género hace referencia a la construcción social del sujeto, entonces es posible establecer una relación estrecha entre género y economía, y es que el sujeto económico no está libre de reproducir las características o roles socioculturales asignados a las personas en función de su sexo.

Partiendo de ese concepto de economía, la historiadora Joan Scott desarrolla una definición de género idónea para estudiar la economía desde dicha categoría; en primer lugar, entiende al género como el espacio primario por medio del cual se articulan las relaciones de poder o que ha facilitado la significación del poder (Scott, 1990), la aplicación de esta definición a la economía sugiere que la forma de cómo se asume y distribuya el poder en el género determinará las relaciones de poder entre los sujetos y los agentes económicos, por lo tanto, comprender esa fuente primaria de significación del poder nos permite explicar muchas de las desigualdades de género presentes en la economía.

En segundo lugar, plantea que el género es un factor constitutivo de las relaciones sociales basadas en la diferencia sexual y que se desarrolla a través de la interrelación de cuatro elementos: símbolos culturalmente disponibles, conceptos normativos, instituciones y organizaciones sociales, y la identidad subjetiva individual y colectiva. El primer elemento hace referencia a los mitos y representaciones simbólicas que evocan determinadas actuaciones de las personas según el sexo; los conceptos normativos, exponen las interpretaciones 
de los significados de los mitos y símbolos a través de declaraciones normativas que condicionan o avalan los comportamientos y roles asignados a las personas; las instituciones y organizaciones sociales, en su papel de vigilantes de las normas y reglamentaciones, a la vez reproductoras y perpetuadoras de las significaciones del poder y las relaciones de género (Scott, 1990); y la identidad, implica el proceso de reconocer y asumir la pertenencia al género que ha sido asignado y al colectivo en cual el sujeto ha sido clasificado.

La economía, por una parte, es un espacio de interacción entre las personas, las cuales vienen marcadas por los símbolos que evocan representaciones y por la pertenencia identitaria asumida, están condicionadas por las normas, instituciones y la organización de la sociedad; en este sentido, el sujeto económico, no necesariamente actúa bajo una racionalidad netamente económica sino que se desenvuelve a la luz de los cuatro elementos constitutivos del género y esto conduce a posiciones desiguales de los géneros en la economía. Por otra parte, la economía, junto la familia y la política tienen un carácter institucional y forman parte de la organización social (Scott, 1990); por lo tanto, influyen sobre ella los tres elementos, así como está tiene la capacidad de influir en la relaciones de género y de poder preestablecidas y cargadas de desigualdades.

Considerando los aportes de Scott, desde su definición de género, se deduce que la economía es una disciplina que no está absuelta de las relaciones de poder que suscita el género porque es un espacio en donde interactúan sujetos y agentes económicos determinados por los elementos constitutivos del género y es una institución social que reproduce y determina las relaciones de género y al sujeto mismo.

Teniendo claro esta noción de género, nace la pregunta sobre quién o quiénes deberían ser los sujetos de estudio en la economía desde una perspectiva de género. En la mayoría de estudios sobre género y economía se parte de la noción de género que hace referencia a las características socialmente construidas sobre la base de la diferencia sexual: hombre y mujer; es decir, el género se refiere al conjunto de mandatos, reglamentos, normas, creencias, roles que la sociedad y/o la cultura atribuye a lo femenino y masculino; de esta manera la perspectiva de género en la economía se ha limitado al análisis de las relaciones de poder entre hombre y mujeres, al análisis de las políticas y fenómenos económicos e impacto de los mismos sobre ambos género; con la economía feminista el sujeto económico se reviste de género y no se presenta como ese sujeto etéreo y neutral como tradicionalmente se presenta en los textos de economía.

Es importante destacar que la economía tradicional tiene una carga altamente masculina en el sentido que ha centrado su interés en actividades realizadas 
por los hombres, es ejercida mayoritariamente por éstos tanto en el campo positivo como normativo y parte del principio de hombre proveedor por lo que consecuentemente esto genera como resultado una poca neutralidad de política económica en términos de género. Ante esa visión androcéntrica las feministas han introducido un nuevo marco de análisis para la economía que considera todos los aspectos planteados por Scott y visibiliza el aporte de las mujeres a la economía.

Con la introducción de la perspectiva de género en la economía, el sujeto económico se presenta bajo dos determinadas identidades de género, por lo que la mayoría de estudios sobre género y economía se desarrollan a partir desde una concepción binaria del género, en donde el sujeto económico es hombre o es mujer; no obstante, la filósofa Judith Butler, plantea que "aunque los sexos parezcan ser claramente binarios es su morfología y constitución (lo que tendrá que ponerse en duda), no hay ningún motivo para creer que también los género seguirán siendo sólo dos" (Butler, 2007), género no se reduce a la identidad masculina y femenina, tanto los estudios antropológicos, la biología y la psicología evidencian que existen muchas más identidades genéricas o géneros, así como más de dos sexos; asumir el binarismo de género en la economía implica marginar al resto de géneros y suponer que la vivencia de estas personas en la esfera económica es igual a la masculina o femenina.

Romper con el binarismo hombre-mujer en las ciencias sociales y la economía es una necesidad a fin de integrar en el análisis económico a los otros géneros y entender cómo estos se insertan en la economía, cómo la política económica asegura sus derechos en iguales condiciones con respecto a los géneros tradicionalmente reconocidos y la conciliación del desempeño laboral/ profesional con la sexualidad; es asumir que el sujeto económico no es asexuado.

Comprender que en la economía las personas no se reducen a un sujeto masculino y otro femenino, implica entender al género como una "categoría analítica abstracta aplicable a la construcción de la masculinidad, la feminidad, la andrógina u otras categorías socio-biológicas definidas en cada sociedad que permite estudiar los roles, estereotipos, relaciones de poder y estratificaciones establecidas" (Martín 2006) Aplicar esta noción de género a la economía nos desvelará que los heterosexuales, transexuales, bisexuales, lesbianas y homosexuales no viven de igual manera su participación en la economía, que las condiciones para el logro del bienestar material/personal difiere para cada género, y que las instituciones socioeconómicas, como el mercado de trabajo, integran una serie de mecanismos de discriminación que coartan las libertades de los mismos.

Hasta a aquí se han planteado dos dimensiones del género, la primera como una categoría de análisis para entender las relaciones de poder y la construcción 
del sujeto; y la segunda, el género como una categoría de identidad del sujeto económico que transciende más allá de la concepción binaria del mismo. Por último, queda por entender el carácter reglamentario de este a través de un orden de género que opera en la sociedad, regula y condiciona al sujeto, su sexualidad y la identidad propia.

Butler sostiene que el género "requiere e instruye su propio y distinto régimen regulador y disciplinador": (1) que responde y está al servicio de otro tipo de reglamento, (2) en el cual se producen y normaliza la masculinidad y feminidad, (3) y no necesariamente tiene un carácter universal y estático ya que se ve influenciado por aspectos étnicos, sexuales, de clase y regionales; el sujeto y los cuerpos que son producidos o adaptados a ese reglamento/ orden de género pueden estar condicionados, marginados y discriminados en la medida se desvíen de la norma ya que el orden funciona como una condición de inteligibilidad cultural para el sujeto (Butler 2007; Butler, 2006).

Ese orden de género se caracteriza en cierta medida por instaurar la heterosexualidad como una norma obligatoria y regidora de la vida, que implica, por una parte, relaciones diferenciadas y de subordinación, por otra, una visión binaria del género, lo que en cierta medida explica el porqué muchos de los estudios sobre género y economía se centran en el sujeto femenino o masculino heterosexual. Pero esa visión binaria del género, el sujeto masculino y femenino no gozan de igualdad de condiciones y oportunidades, lo cual es posible observarlo en la economía, en donde existe de una clara jerarquización valorativa del trabajo según el género que lo desempeñe.

Adicionalmente, el orden de género se basa en una jerarquización de la sexualidad que se traduce consecuentemente en una jerarquización de género y del reconocimiento que tiene el sujeto en la sociedad. La antropóloga Gayle Rubin expone la existencia de una jerarquía sexual, en cuya cima se encuentran los heterosexuales reproductores casados -considerado lo normal, natural y la sexualidad buena y sana-, seguidos por los heterosexuales que no pertenecen a esa primera categoría y las parejas estables homosexuales, mientras que en el otro extremo se ubica lo peor, la personas que transgreden la "sexualidad sana" o que se mueven en el campo del sexo malo o en la sexualidad anormal, pecaminosa o extravagante; este tipo de jerarquización tiene su efecto en términos sociales, ya que los de la cima gozan del reconocimiento legal, respetabilidad y beneficios institucionales, en tanto que en la medida se desciende, el sujeto pierde reconocimiento, legalidad y es estigmatizado (CollPlanas, 2010).

Esta jerarquización aplicada al sujeto económico y en términos de género, indicaría que dentro de la heterosexualidad existe una subjerarquización en donde el reconocimiento y valor del trabajo del hombre heterosexual es superior 
al reconocimiento y valor del trabajo de la mujer heterosexual. Asimismo, la economía como elemento constitutivo del género condiciona el reconocimiento e inserción socioeconómica del sujeto según el tipo de sexualidad e identidad genérica con la que se identifique; o la presencia de esa jerarquía en la economía obliga al sujeto a renunciar a su sexualidad o desterrarla a la clandestinidad a fin de mantener sus respetabilidad y reconocimiento profesional y laboral. A esto habría que agregar, que si bien la homosexualidad contraviene la norma y se ubica en una escala inferior del reconocimiento, el sujeto masculino en el ejercicio del poder antes que homosexual o heterosexual es homosocial, ${ }^{3}$ esto repercute en que la línea fronteriza entre el hombre heterosexual y homosexual sea frágil en la consolidación de una alianza para sostener la posición masculina dentro de las diferentes dimensiones del poder.

Los aspectos antes expuestos sobre el orden de género responden también a los intereses de la reglamentación patriarcal de la sociedad, en donde la heterosexualidad y la autoridad masculina constituyen dos de sus principales premisas (Menjívar, 2004), reglamenta la sexualidad, se basa sobre la valoración de lo masculino y desvalorización de lo femenino y organiza la fuerza de trabajo en función de la división sexual del trabajo; considerando los aportes de Gil de San Vicente (2001) el patriarcado y/o el orden de género se ajusta a las necesidades del de sistema económico en cual se instituye, así, por ejemplo, en sociedades capitalista es posible determinar que los mecanismos de opresión, explotación, dominación tienen la marca del género. Según Hlupekile (2002), el patriarcado comprende una serie de componentes que legitiman la existencia de su propio gobierno patriarcal y autoridad masculina a saber: creencia de la superioridad masculina, instrucciones de Dios, tradición sobre quien ejerce el poder, los intereses de los hombres como sinónimo de interés general, división del trabajo y disciplina y coerción.

\section{Avances en el marco institucional y legal}

Los últimos dos años ha sido un periodo importante en la generación de acciones en el plano legal e institucional para promover la igualdad de género o para

3. Siguiendo en parte a Eve Kosofsky Sedgwick, entiendo por homosocial a las alianzas o vínculos creados/establecidos entre los hombres para ser los únicos que controlan el poder y para restringir el acceso al mismo por parte de la alteridad. Los hombres ante la necesidad de ser propietarios del poder y posicionar el poder fálico, la identidad sexual de éstos durante el establecimiento de las alianzas para regentar el poder deja de tener valor, lo que predomina aquí es que el poder siga en manos de quienes por "naturaleza" son los poseedores del falo sin importar si el objeto/sujeto del deseo de estos hombres es heterosexual u homosexual. Valga aclarar que no estoy planteando de hecho relaciones armoniosas entre el hombre heterosexual y el homosexual, pero que pueda que la noción de hombre propietario del falo este por encima -en algunos aspectos de la vida social- de la identidad sexual; pueda también que el acceso al poder que por naturaleza da el falo al hombre venga acompañado de la negación de la homosexualidad o el silencio de la misma. 
garantizar los derechos de las mujeres; hasta antes de 2010 habían sido escasos los esfuerzos del Estado por hacer un abordaje serio sobre las desventajas que las mujeres sufren con respecto a los hombres en las diferentes esferas de la vida, es más, entre 1998 y 1999 en materia de salud sexual y reproductiva las mujeres vieron reducidos sus derechos cuando el Estado decidió reformar el Código Penal y la Constitución a fin de cambiar el régimen de regulación del aborto bajo el sistema de indicaciones por uno en donde se penaliza o prohíbe cualquier tipo de aborto.

Sólo entre 2010 y 2011, el Estado dio un salto significativo en materia de derechos para las mujeres al aprobar Ley de Igualdad, Equidad y Erradicación de la Discriminación contra las Mujeres y la Ley Especial Integral para una Vida Libre de Violencia; por otra parte, el ISDEMU ha renovado y actualizado su Política Nacional de las Mujeres -PNM- que supera los vacíos de la administraciones pasadas en cuanto a las temáticas abordadas; asimismo, se han implementando otras acciones orientadas a combatir la discriminación de género y para mejorar el acceso de las mujeres a determinados servicios públicos. Es importante reconocer la labor propositiva del movimiento feminista y de mujeres en la generación de estos cambios ya que muchos de ellos han sido parte de sus reivindicaciones políticas.

Aunque es muy pronto para determinar el impacto real de estos nuevos instrumentos legales e institucionales sobre la vida de las mujeres y en la igualdad de género, en esta oportunidad se expone el abordaje de la dimensión económica -excepto en el Plan Quinquenal de Desarrollo- a fin de dar a conocer cuáles son las prioridades que asume el Estado para garantizar la igualdad de oportunidades y el empoderamiento económico de las mujeres, así como algunas observaciones al diseño o contenido de los mismos.

\subsection{La dimensión de género en el Plan Quinquenal de Desarrollo 2010-2014}

El Plan Quinquenal de Desarrollo -PQD- es el principal documento rector de la política pública salvadoreña del gobierno presidido por Mauricio Funes Cartagena. Durante su periodo presidencial (2009-2014), en este se exponen las estrategias, objetivos y metas a lograr durante el periodo señalado y el cual hay una importante referencia al género, así como una prioridad por contribuir a reducir las desigualdades de género.

Si bien la igualdad de género está señalada a lo largo del documento, cabe preguntarse cuál es la interpretación de género que expone el documento y si realmente contribuye a la prioridad del Gobierno de El Salvador de reducir las desigualdades; a fin de dar una respuesta a esta interrogante este apartado 
expone las principales referencia que el documento hace al género así como una aproximación muy somera a cómo se entiende el género considerando algunos elementos de la metodología de Marcos Interpretativos de Política. ${ }^{4}$

El PQD está estructurado en cuatro partes; la primera, expone el punto de partida del gobierno actual, que en resumidas cuentas es el modelo de desarrollo económico y social sustentado en las políticas de corte de neoliberal e implementado desde 1989 por la gestión de gobierno liderado por el partido Alianza Republicana Nacionalista -ARENA-, ${ }^{5}$ así como el contexto de la crisis financiera mundial; en esta parte, en cuanto a la igualdad de género el Gobierno concluye que el modelo que ha regido el desarrollo del país ha basado su competitividad en la existencias de inequidades de género, ha fracasado en el logro de la equidad y evidencia una incidencia mayor de las mujeres en la pobreza y la desigualdad.

La segunda parte, desarrolla las apuestas estratégicas, prioridades, objetivos y metas; para la definición de estos aspectos el Gobierno se basa en una visión de país a mediano y largo plazo y centra los objetivos del PQD en sentar las bases de un nuevo modelo de desarrollo y en la profundización y consolidación de la democracia. Asume como propias las apuestas estratégicas a 2024 acordadas por el Consejo Económico y Social -CES-, en tres de las nueve de ellas hay compromisos en materia de género: (1) contar con una población sana, educada y productiva en donde el Gobierno se compromete a implementar una política transversal de género; (2) construir una sociedad equitativa, incluyente y tolerante, lo cual incluye la equidad de género, así como asegurar la participación de las mujeres en las diferentes dimensiones de la vida y (3) lograr la paz social y un ambiente de seguridad humana, el compromiso reside en ejecutar una estrategia integral que contribuya a reducir la violencia social, de género e inseguridad (GOES, 2011).

Para el periodo presidencial de Mauricio Funes, el CES definió un conjunto de áreas prioritarias que forman parte del $P Q D$, entre las que hacen referencia al género son:

4 Esta metodología consiste en interpretar los procesos discursivos respecto a una situación, problema o fenómeno dentro de una política de tal manera que es posible identificar las prioridades y actores consideradas y excluidos, dichas exclusiones son expresiones dominantes de poder (Bustelo, 2009); asimismo, permite identificar los elementos ideológicos y culturales en los procesos de acción colectiva, en otras palabras, procura evidenciar la interiorización, reproducción, difusión de elementos culturales e ideológicos en la acción social (Chihu, 2007) y en las intervenciones de política. Con esta metodología es posible identificar si existe un compromiso real por parte de los hacedores de la política con las aspiraciones de igualdad entre los géneros; así como también el potencial de la política en cuestión como reproductora del orden de género imperante.

5. ARENA estuvo liderando el Órgano Ejecutivo desde 1989 hasta 2009, año en que el partido Frente Farabundo Martí para Liberalización Nacional -FMLN- gana las elecciones presidenciales con Mauricio Funes como candidato presidencial. 
- La reducción significativa y verificable de la pobreza, la desigualdad económica y de género y la exclusión social.

-La prevención efectiva y el combate de la delincuencia, la criminalidad y la violencia social y de género. (GOES, 2011)

En relación a los objetivos si bien no hay una referencia explícita en cuanto a la igualdad de género, podría indicarse que esta ha sido considerada dentro del objetivo de reducción de la pobreza y aumento de la cobertura de los servicios sociales básicos; por otra parte, en el objetivo de reducción del desempleo y subempleo hay una referencia a la promoción del trabajo decente el cual incorpora la dimensión de género.

En coherencia con los objetivos, el Gobierno cuantifica y define las metas que espera lograr durante el quinquenio; sin embargo, estas se limitan al escenario macroeconómico sin especificar como esos resultados se distribuiría entre hombres y mujeres.

En la tercera parte del PQD se expone la estrategia de intervención que se concretiza en acciones en los siguientes componentes: a) el Sistema de Protección Social Universal y las políticas sociales estratégicas, b) el Sistema Financiero de Fomento para el Desarrollo, c) las políticas públicas macroeconómicas y sectoriales, d) la estrategia de desarrollo productivo, e) políticas de seguridad, de convivencia democrática y de proyección internacional y f) la inversión pública en programas y proyectos estratégicos (GOES, 2011: 52). ${ }^{6}$ A fin de que estas intervenciones contribuyan a la igualdad de género, el Gobierno aclara y establece que los temas de género son transversales a la estrategia, por lo que no se abordan de manera separada sino que están incorporados en cada uno de los componentes; asimismo, declara que a través del ISDEMU se impulsará una Política Nacional de las Mujeres -PNM-:

La política tendrá como finalidad potenciar el desarrollo integral de las mujeres salvadoreñas en todos los espacios de la sociedad en condiciones de equidad y de igualdad con los hombres y se operativizará a partir de dos grandes objetivos estratégicos. En primer lugar, la promoción de políticas públicas con enfoque de género y, en segundo lugar, la promoción del cumplimiento de los compromisos internacionales del Estado salvadoreño en materia de derechos humanos de las mujeres, no discriminacióndegéneroydeprevención, atención, sanciónyerradicación de todas las formas de violencia contra las mujeres (GOES, 2011).

6 Esta versión no incorpora una revisión sobre qué aspectos o acciones de cada uno de los componentes de la estrategia de intervención realizan alguna mención concreta a la igualdad de género; aunque el PQD indica que el género es transversal, en la lectura general de los componentes se identifican algunas acciones positivas. 
Con esta disposición el ISDEMU asume una gran responsabilidad en cuanto a asegurar que la estrategia de intervención y las políticas públicas sean efectivas en materia de igualdad de género y favorables para el empoderamiento económico, político y cultural de las mujeres; sin embargo, cabe preguntarse si esta responsabilidad asignada excede a las condiciones presupuestarias de la institución para llevarla a cabo y a su estatus de organismo público subordinado, vale recordar que las relaciones interinstitucionales del sector público están marcadas por las relaciones de poder, y si este viene marcado por el género, es probable que en determinadas circunstancias o acciones el ISDEMU se vea limitado en su capacidad de actuación y de garante de la igualdad de género.

La cuarta parte, describe la forma de cómo se realizará el proceso de coordinación interinstitucional y el proceso de seguimiento y evaluación del $P Q D$. En el texto de esta parte no se ha identificado ninguna mención explícita al género como categoría de análisis para el seguimiento y evaluación de PQD.

Al evaluar el PQD a la luz de la metodología de Marcos Interpretativos de Política, ${ }^{7}$ se deriva, en primer lugar, que en cuanto al género las preocupaciones del Gobierno están centradas en las desigualdades y en la violencia de género; las desigualdades de género tienen un enfoque fuertemente economicista, las referencias a las desigualdades en plano del reconocimiento y representación/ participación son muy escasas o poco tratadas en el texto, es decir que hay un interés prioritarios por superar la brechas de género en la economía y el mercado, sin abordar los aspectos cultural/simbólicos y de representación política que también influyen en el sostenimiento de las desigualdades económicas.

Segundo, la visión economicista presente en el documento pierde de vista al orden de género como determinantes de las desigualdades y de la violencia; en la primera parte del PQD las desigualdades/inequidades de género son entendidas como una condición necesaria para la competitividad del modelo económico y social, lo que consecuentemente ha limitado el avance hacia un desarrollo integral de la sociedad salvadoreña; explícitamente no hay una referencia a cómo los valores patriarcales, la heteronormatividad, la dominación masculina configuran un entramado de intuiciones sociales y simbólicas que reproducen y sostienen las desigualdades.

Tercero, en el texto el género es concebido desde una visión binaria; estos son vistos como opuestos, heterosexuales, jerárquicamente tienen posiciones distintas en el ejercicio del poder y se constituyen como una norma social o

7. Es importante aclarar que este constituye un ejercicio somero sobre el texto del $P Q D$, un estudio más profundo se desarrollará posteriormente. En este primer ejercicio sobre el género en el marco interpretativo del $P Q D$ se ha realizado en función de las siguientes preguntas guías: ¿qué problema se aborda? ¿qué noción de género predomina? ¿quién habla en el texto? ¿Quiénes participan? ¿quién tiene el problema? ¿qué causa el problema? ¿quién es la población destinataria? ¿contradicciones entre lo escrito y las iniciativas reales en materia de igualdad? 
de inteligibilidad de lo humano; en el primer apartado se señaló que el género como categoría de identidad no se limita a lo masculino y femenino, Butler señala que no necesariamente el binarismo sexual se traduce en un binarismo de género, romper esa lógica así como superar la noción de género como la marca cultural adherida al sexo bilógico es abrir las posibilidades y aceptación de las múltiples formas de ser persona y que estas deben ser objeto de la políticas pública en todos sus ámbitos; la identidad transexual, lesbiana, gay, bisexual no es meramente sexualidad, deseo o placer, están configuradas por el contexto social -entre otros elementos- al igual que la masculina y femenina heterosexual.

Cuando en el PQD se habla de desigualdad de género es clara la referencia a un problema de desigualdades entre hombres y mujeres heterosexuales, en tanto que los demás géneros no suelen ser objetos explícitos de la política, especialmente en los dos temas en donde las alusiones al género son más frecuentes: economía/mercado de trabajo y violencia de género, acaso ¿los transexuales, lesbiana, gay, bisexual no sufren violencia de género? ¿Éstos están libres de la discriminación en el mercado de trabajo? ¿Éstos no ven regulada su identidad de género, la vivencia de la sexualidad y actuación como sujeto económico por la economía y el mismo orden de género?

Por otra parte, si bien la noción de género reside en la dualidad masculina femenina, son las mujeres el grupo objetivo de las intervenciones en materia de género o las que tienen el problema, lo cual da lugar a que la política de género se confunde con la política de la mujer, las cuales son o deberían ser totalmente distintas pero articuladas. No se cuestiona el interés por las acciones orientadas a que las mujeres superen las desigualdades, pero si la ausencia de que no se reconozca que la construcción social de la masculinidad tiene una responsabilidad en el estado de las desigualdades y en la discriminación contra las mujeres, por lo tanto también los hombres deberían ser sujeto y objeto de las intervenciones de género.

Por último, el análisis entre las aspiraciones/compromisos que se despliegan en el texto/discurso del PQD y la práctica de la política, aporta elementos importantes para evaluar o conocer la voluntad política del Gobierno en cuanto a impulsar cambios para eliminar los obstáculos que limitan la igualdad y los derechos de las mujeres.

Si bien el PQD hace referencia recurrente a mejorar la condiciones de vida de las mujeres, así como a contar con una Política Nacional de la Mujer que promocione los compromisos internacionales del Estado en cuanto a los derechos de las mujeres, este ha mostrado resistencia para mejorar el marco legal sobre el aborto. Como se señaló anteriormente, a finales de los noventas 
las mujeres salvadoreñas vieron reducidos sus derechos, El Salvador pasó de contar con un ordenamiento jurídico bajo un sistema de indicaciones que despenaliza el aborto bajo determinadas circunstancias a un sistema rígido o que sanciona/penaliza cualquier caso. Tanto el movimiento feminista como el Comité de Derechos Económicos, Sociales y Culturales ${ }^{8}$ y Comité de la CEDAW ${ }^{9}$ han instado al Estado a que revise la legislación actual y promueva un diálogo sobre la misma dada la preocupación de que se está poniendo en peligro la vida de las mujeres y debido a la poco eficacia de los programas de educación sexual y reproductiva; no obstante, el Estado hasta la fecha ha evadido las sugerencias de los Comités y las demandas desde el movimiento feminista así como la iniciativa desde el mismo funcionariado.

Al igual que los gobiernos de las gestiones pasadas (1989-2009) que se escudaban en la Constitución para no ratificar algunos convenios fundamentales de la OIT, el Gobierno actual recurre a la misma estrategia para evadir su responsabilidad de generar un diálogo sobre el aborto indicando que lo establecido en el Art. 2 de la Constitución ${ }^{10}$ define la posición del Estado sobre dicho tema, lo que consecuentemente ha generado que la PNM carezca de acciones concretas que impulsen un diálogo sobre el aborto y para la flexibilización de la legislación. Este caso -así como el enfoque economicista del PQD- nos proporciona un indicio de quién es la voz dominante tanto en el texto como en la implementación de las políticas, cuestiona hasta qué punto el reconocimiento de las mujeres en el texto puede resultar figurativo si no hay mecanismos claros de representación y participación política de las mismas en la tomas de decisiones y si el Estado es capaz de asumir aquellos temas de la igualdad de género que son una afrenta al fundamentalista moral religioso, que por lo general suele ser reproductor de relaciones de poder y género desiguales entre mujeres y hombres.

\subsection{Acciones para la igualdad de género en ámbito económico y mercado de trabajo $^{11}$}

Durante los últimos dos años, el Gobierno ha desarrollado múltiples acciones orientadas a reducir las desigualdades de género con especial atención a

8 Para más detalle véase: Comité de Derechos Económicos, Sociales y Culturales (2006). Observaciones finales del Comité de Derechos Económicos, Sociales y Culturales: El Salvador. http://www2.ohchr.org/english/bodies/cescr/cescrs37.htm

9. Para más detalle véase: Comité de la CEDAW (2008) Observaciones finales del Comité para la Eliminación de la Discriminación contra la Mujer: El Salvador. http://www2.ohchr.org/english/bodies/cedaw/cedaws42.htm

10. Establece que "El Salvador reconoce a la persona humana como el origen y el fin de la actividad del Estado, que está organizado para la consecución de la justicia, de la seguridad jurídica y del bien común. Asimismo reconoce como persona humana a todo ser humano desde el instante de la concepción. En consecuencia, es obligación del Estado asegurar a los habitantes de la República, el goce de la libertad, la salud, la cultura, el bienestar económico y la justicia social"

11. Si bien estas acciones o políticas son susceptibles de analizarse desde los marcos interpretativos, sólo se ofrece un breve comentario de estas en cuanto al propósito, objeto, sujeto/objeto de igualdad sobre el que intervienen. 
las mujeres; en esta oportunidad se enuncian las que han tenido una mayor visibilidad y que formarían parte de la herencia del Gobierno actual. ${ }^{12}$

- Política Nacional de las Mujeres

La PNM asume los objetivos que el PQD asigna a la política y centra su intervención en seis áreas: economía, violencia, educación, salud, cuidado/ protección social y participación ciudadana y política. En materia económica presenta un amplio catálogo de medidas con las que se espera contribuir a la autonomía económica de las mujeres, distribuidas en tres componentes de intervención: discriminación en el mercado de trabajo, desarrollo productivo y empresarial, y salarios y poder adquisitivo. Asimismo, en el área de cuidado y protección social se detallan acciones relacionadas al trabajo, que buscan ampliar la cobertura del sistema de protección social y la corresponsabilidad en el trabajo de cuidado, entre otras.

Dada la magnitud de acciones que se presentan en la PNM es importante aclarar que el logro de las mismas no es responsabilidad única del ISDEMU, como se señala en la Política, la implementación de las medidas recae sobre los ministerios e instituciones gubernamentales que tienen bajo su responsabilidad las áreas que toca la PNM, el ISDEMU asume una función de rectoría que propiciará las condiciones para echar andar la política y el seguimiento de la misma. Si los ministerios no están sensibilizados en cuanto al género las aspiraciones de la PNM serán fallidas, de tal manera que el compromiso explícito del Gobierno en el $P Q D$ de implementar una política transversal de género se vuelve una condición necesaria para la implementación y éxito de la PNM.

- Ley de Igualdad, Equidad y Erradicación de la Discriminación Contra las Mujeres

En marzo de 2011, fue ratificada por la Asamblea Legislativa la Ley de Igualdad, Equidad y Erradicación de la Discriminación Contra las Mujeres, cuyo propósito es “crear las bases jurídicas explícitas que orientarán el diseño y ejecución de las políticas públicas que garantizarán la igualdad real y efectiva de mujeres y hombres, sin ningún tipo de discriminación, en el ejercicio y goce de los derechos consagrados legalmente".

El Capítulo IV de la Ley expone los aspectos en materia económica, en donde el Gobierno buscará la igualdad y no la discriminación de la mujeres en la participación económica mediante la coordinación con los organismos o instancias responsables de la promoción del desarrollo económico, así como

12. Hay otras iniciativas que vale la pena señalar y que no se han considerado: Comunidades Solidarias, Programa de Apoyo Temporal al Ingreso y transversalización de género en la Estrategia de Desarrollo Productivo. 
también mediante acciones que favorezcan la participación igualitaria de hombres y mujeres en el acceso y control de los medios de producción, y a través de incentivos al sector financiero buscará fomentar el emprendimiento económico de las mujeres. Además, busca intervenir en la configuración de una oferta y demanda de fuerza bajo los principios de igualdad y no discriminación, haciendo énfasis en temas como: derechos laborales, contratación, formación profesional, inspección laboral, oportunidades de empleo, salarios, trabajo doméstico y acoso sexual y laboral.

Por otra parte, en los capítulos V y VI se detallan otras disposiciones vinculadas a la dimensión económica como son el trabajo doméstico, la seguridad social de la población trabajadora y la participación de las mujeres en el desarrollo rural.

En materia de economía pública, el presupuesto es un instrumento idóneo para fomentar la igualdad, por ello es importante que los presupuestos de la Administración Pública cuenten con una perspectiva de género a fin de evitar que las líneas presupuestarias de gasto o inversión pública estén marcadas por un sesgo de género. Si bien la Ley en el Art. 13 expone que "La presente ley establece que la elaboración de los presupuestos con enfoque de género, deberán tener en cuenta las diferentes necesidades de mujeres y hombres, para potenciar la igualdad y acciones equitativas que hagan realidad los compromisos gubernamentales con la equidad y la igualdad". No está del todo claro si existe una obligatoriedad previa para que la Administración Pública elabore y analice sus presupuestos desde el género, ${ }^{13}$ si la evaluación o análisis de estos constituye un requisito para la aprobación, si se instaura o no una comisión responsable en el Ministerio de Hacienda para el caso del presupuesto general; la Ley si establece que en el presupuesto público deberán disponerse recursos tanto para el cumplimiento de la misma como para que el ISDEMU realice las funciones que en el marco de la Ley se le adjudican.

\section{- Ciudad Mujer}

Ciudad Mujer podría definirse como instrumento de política que busca integrar y territorializar los servicios públicos para las mujeres de tal manera que puedan tener un mejor acceso. El documento conceptual establece que el objetivo de este programa es: "contribuir a mejorar las condiciones de vida de las mujeres salvadoreñas, mediante la facilitación de servicios que satisfagan sus necesidades $e$ intereses estratégicos, ofrecidos o coordinados por los Centros de Atención Integral ubicados estratégicamente en el país, conocidos como Ciudad Mujer"(SIS); esta institución está bajo la conducción de la Secretaria de

13. Es decir, la Ley establece que en la elaboración de los presupuestos con enfoque de género se tendrán en cuenta las necesidades de hombres y mujeres; pero parece tener un vacío en cuanto a establecer un mandato directo al gobierno central y los locales para que elaboren sus presupuestos con en foque de género. 
Inclusión Social -SIS- y en coordinación con las instancias públicas que prestan servicios dentro de los centros.

Los centros tienen 5 módulos de atención: promoción de los derechos, salud sexual y reproductiva, empoderamiento económico, prevención y atención de la violencia contra las mujeres y sala de atención infantil; en cuanto a la dimensión que nos compete en las áreas de intervención son derechos laborales, fomento de la empresarialidad de las mujeres, intermediación laboral, formación profesional, servicios de desarrollo empresarial y microfinanzas.

De la revisión del documento conceptual de Ciudad Mujer y la PNM se deriva una aparente ${ }^{14}$ separación técnica y política entre Ciudad Mujer y el ISDEMU. Por lo tanto, resulta un poco extraño que Ciudad Mujer como un instrumento de política pública no se enmarque como parte del ISDEMU ${ }^{15}$ quien es la instancia responsable y rectora del componente de desarrollo de las mujeres en la política pública, esa separación se constata cuando se observa que en el nivel políticoestratégico del programa la SIC figura como responsable y el ISDEMU como una instancia con la que se coordina.

Por otra parte, en el documento conceptual no es posible identificar una referencia clara al espíritu filosófico y contenido de la actual PNM como base para la definición de Ciudad Mujer, pero sí a través del PQD indicando que el programa es un esfuerzo de traducir las políticas públicas y de la mujer al territorio; en cuanto la PNM, a pesar que Ciudad Mujer es uno los programas insignia del Gobierno del Presidente Funes y que ha logrado reconocimiento internacional, en la PNM no hay ningún párrafo o apartado en donde se cite el programa o se indique que Ciudad Mujer será una de las instancias que implementará la política bajo la rectoría del ISDEMU.

- Decreto N. 56 sobre disposiciones para evitar toda forma de discriminación en la administración pública, por razones de identidad de género $\mathrm{y} / \mathrm{o}$ orientación sexual

El progreso del marco legal que garantice los derechos del colectivo de lesbianas, gays, transexuales y bisexuales ha sido muy lento en el país, por lo que esta iniciativa sienta un precedente muy importante en la inclusión de estas personas como ciudadanas. El Decreto Ejecutivo No. 56 de mayo de 2010 prohíbe toda forma de discriminación por razón de identidad de género y/o orientación sexual dentro de la Administración Pública, manda a dicha instancia

14. Aparente porque para esta conclusión sólo me he remitido a los documentos en cuestión y no he realizado entrevistas en las instancias respectivas que me permitan aclarar la duda.

15. Pueda que esto se explique por el hecho de que Ciudad Mujer fue una de las promesas más importantes en la campaña electoral del Presidente Mauricio Funes y a fin de asegurar el éxito de esta posiblemente decidieron ubicar el programa dentro de la Secretaria de Inclusión social la cual es presidida por la Primera Dama de la República. 
a que revise sus programas, políticas, proyectos y corrijan cualesquier indicios de discriminación directa o indirecta así como a generar una cultura de respeto; faculta a la SIC para que brinde asesoramiento a las administraciones cuando lo requieran o de manera oficiosa.

Considerando que toda persona tiene derecho a la no discriminación por razón de género y/o orientación, la tarea pendiente del Estado es ampliar este derecho al sector privado -en donde, por ejemplo, se concentra el $89 \%{ }^{16}$ de la fuerza de trabajo ocupada del área urbana del país-, dar el salto de un decreto ejecutivo y a un decreto de ley de la república que universalice el derecho con el propósito de contar con mayor garantía jurídica. Aunque soy de la idea que la sexualidad es un elemento constitutivo del género y que por lo tanto no debería de existir una separación entre identidad de género y orientación sexual -asumir las orientaciones como géneros-, es necesario que el marco legislativo, constitucional e institucional reconozca explícitamente el derecho a la no discriminación por orientación sexual, que las lesbianas, homosexuales, bisexuales y transexuales sean objeto de derecho en iguales condiciones que la población heterosexual en todos los ámbitos de la vida.

- Régimen especial de salud y maternidad para los trabajadores domésticos

El sistema de protección social del país está muy vinculado al empleo formal, esto repercute en que una parte importante de la fuerza de trabajo quede fuera del régimen e indudablemente afecta muchos más a las mujeres, debido a su mayor participación en la informalidad y subempleo.

Hasta antes de mayo de 2010, la población trabajadora ocupada en oficios domésticos estaban excluidas del régimen del seguro social junto con personas en trabajos temporales y agrícolas, pero con el Decreto Ejecutivo No 74 "Reglamento de creación y aplicación del régimen especial de salud y maternidad para los trabajadores domésticos" se le facilita el acceso a las prestaciones del Instituto Salvadoreño del Seguro Social -ISSS-. El valor de este decreto es que pretende acercar el derecho a la seguridad social a un sector en donde las mujeres tienen una participación mayoritaria y muchas de ellas provienen de hogares pobres.

El régimen se aplica a la población trabajadora de 14 a 60 años y esta podrá inscribir a las hijas/os menores de 12 años como beneficiarios. Para el financiamiento del régimen se establece una tasa de cotización sobre la remuneración afectada, para la persona empleadora es del $7.5 \%$ y para la trabajadora del 3\%, el pago a cuenta del empleador es deducible del impuesto sobre la renta.

16. Según datos de la EHPM de 2010. 
La debilidad que presenta el régimen es que no marca un carácter de obligatoriedad, ya que establece que las trabajadoras/es en común acuerdo con la persona empleadora podrán solicitar la afiliación al régimen; una observación a señalar es que el acceso a este derecho está condicionado a la voluntad de partes, especialmente a la del empleador dada su posición de poder en la relación laboral, prácticamente lo que establece el régimen es que aquellos empleadores que tengan la buena voluntad de afiliar a sus trabajadoras/es domésticos cuentan con las condiciones institucionales para hacerlo; adicionalmente, el proceso de afiliación es de manera gradual de acuerdo a criterios geográficos, capacidad técnica del ISSS, entre otros.

\section{Estado de la desigualdad de género en el mercado de trabajo ${ }^{17}$}

Considerando lo reciente del marco institucional y legal expuesto anteriormente, se ha optado por caracterizar las desigualdades de género en el mercado de trabajo a través de indicadores que se han derivados de algunos compromisos internacionales asumidos por el Estado en materia de igualdad y progreso de las mujeres, concretamente la CEDAW y la DPAB, que tanto la PNM como la Ley de igualdad los retoman dentro del sus contenidos.

Los componentes considerados para caracterizar el estado de las desigualdades de género son: pobreza en la fuerza de trabajo, trabajo no remunerado, combinación entre trabajo remunerado y no remunerado, ocupación y desempleo, empleo precario, actividad económica, ejercicio del poder y acceso a la propiedad de las empresas, salarios, estabilidad laboral, seguridad social y sindicalización; estas ha sido seleccionadas según las disposiciones de la CEDAW y DPAB en materia económica y en función de la disponibilidad de información estadística oficial desagregada por sexo.

\subsection{Pobreza en la fuerza de trabajo}

La pobreza es una de las preocupaciones presentes en la DPAB, ya que esta suele afectar mucho más a las mujeres y condiciona el estilo de inserción laboral de las mismas. En El Salvador, la incidencia de la pobreza en la fuerza de trabajo -Población en Edad de Trabajar, PET- femeninas es mayor con respecto a la masculina, el $37,8 \%$ de las mujeres en edad de trabajar son pobres o pertenecen a hogares pobres, mientras que los hombres en dichas situación representan el 36,3\% en 2010; como se puede observar en el gráfico 1, si bien en los últimos dos años la pobreza se ha reducido para ambos, la brecha de género se mantiene desfavorablemente para las mujeres; otro dato interesante a destacar, es que en 2010 se rompe la tendencia que ubica a los hogares con jefatura femenina con niveles de pobreza mayores con respecto a los de

17. Este apartado retoma y actualiza los indicadores que fueron presentados en el informe "Mujer y mercado laboral 2010" de ORMUSA. 
jefatura masculina, habría que profundizar hasta qué medida el programa de transferencias condicionadas heredado de la administración pasada, así como la feminización de las migraciones y remesas familiares han contribuido a este cambio.

A fin de superar el sesgo de género que suelen tener los cálculos de pobreza a partir del método de líneas de pobreza, se presenta como indicador adicional el número de personas en edad de trabajar que no reportan ingresos, a 2009 el $47,5 \%$ de las mujeres dentro de la categoría de PET no reportan ingresos, ese porcentaje para los hombres es del 31,5\% (Gráfico 2); esta situación sumada a la división sexual del trabajo repercute que las mujeres permanezcan y tengan mayores niveles de pobreza.

\subsection{Trabajo no remunerado}

El trabajo no remunerado -TNR- constituye la fuerza de trabajo invertida para la reproducción de la misma, el cuidado y el bienestar familiar, por lo general es desempeñando en el ámbito del hogar o espacios vinculados a este. ${ }^{18}$ Los datos señalan que las mujeres tienen una amplia participación dentro del TNR, el $69,6 \%$ de las mujeres y el 5,8\% de los hombres en condición de inactividad se dedican a los quehaceres domésticos y obligaciones familiares (Gráfico 3); vale señalar que la razón más importante de inactividad de los hombres es que estos se encuentran estudiando $(44,6 \%)$ en tanto que para las mujeres es que se dedican al trabajo del hogar $(67,9 \%)$, esta situación impone una desventaja a las mujeres cuando ingresan al mercado de trabajo ya que están menos formadas lo que consecuentemente repercute en menores ingresos o salarios.

\section{Gráfico 1}

Hogares y PET en situación de pobreza

(Porcentajes)

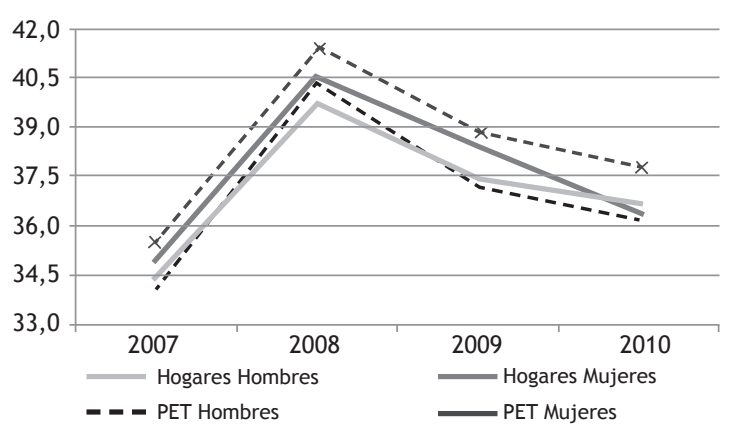

Fuente: Elaboración propia a partir de la EHPM

18. Para estimar el número de personas que se dedican este tipo de trabajo se ha considerado a la Población Económicamente Inactiva que se dedica a quehaceres domésticos y obligaciones familiares. 
Gráfico 2

PET que no reporta algún tipo de ingresos

(Porcentajes)

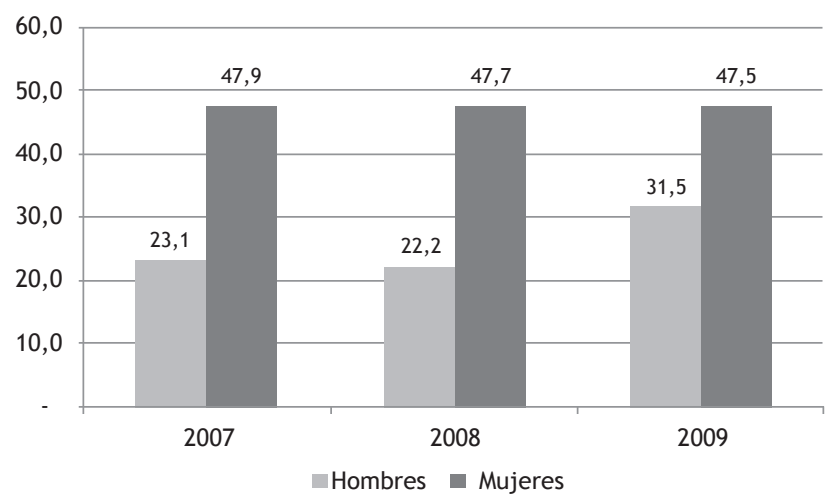

Fuente: Cálculos propios a partir de la EHPM

Gráfico 3

PEI según condición de inactividad y en TNR, 2010

(Porcentaje)

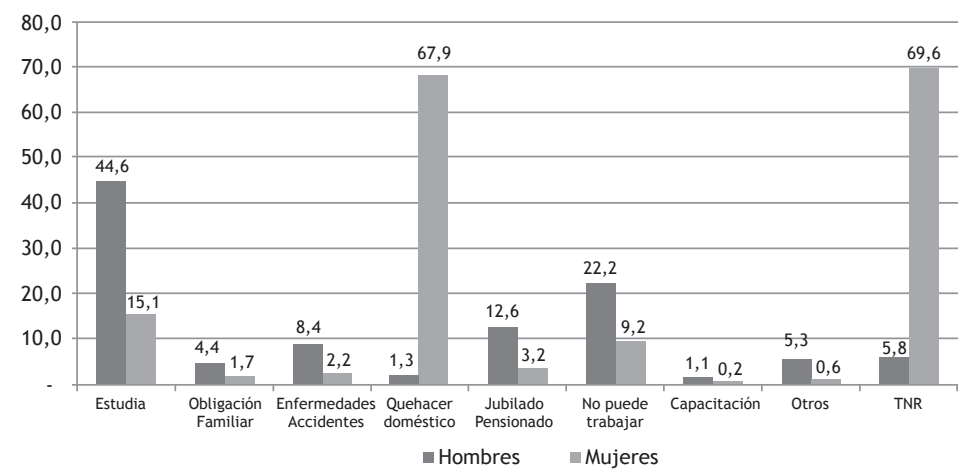

Fuente: Elaboración propia a partir de la EHPM

\subsection{Ocupación y desempleo}

La tasa de ocupación indica el porcentaje de PET que está ocupada o empleada y proporciona una idea sobre en qué medida las personas abandonan la esfera de la inactividad y pasan al trabajo remunerado. Como se puede observar en el cuadro 1, los hombres tienen una mayor participación en el trabajo remunerado al tener una tasa de ocupación del $74,1 \%$, en tanto que la de las mujeres es del $44,8 \%$ esto evidencia la permanencia de la división sexual del trabajo como principio distributivo de las oportunidades, roles y responsabilidades que asumen mujeres y hombres en el sostenimiento de la vida. 
En cuanto al desempleo, las bajas tasas en términos de género que presenta el país se contrastan con altos niveles de empleo precario como se verá más adelante; sin embargo, vale señalar algunos aspectos importantes sobre el comportamiento de las tasas y que merece se profundice al respecto en futuros estudios sobre el mercado de trabajo salvadoreño: a diferencias de la mayoría de países de América Latina la tasa de desempleo femenina es mucho menor que la masculina, se ha revertido la tendencia de la caída de la tasa de desempleo femenina que se venía observando desde los noventas mientras que la masculina se mantiene relativamente estable alrededor del 8\%, por lo tanto ¿ha sido el empleo precario lo que ha permitido la menor tasa de desempleo de las mujeres? ¿El dinamismo en los últimos dos años en el incremento de la tasa femenina es producto de la crisis económica reciente?

Cuadro 1

Tasa de ocupación y desempleo

(Porcentajes)

\begin{tabular}{|l|c|c|c|c|}
\hline \multirow{2}{*}{ Año } & \multicolumn{2}{|c|}{ Tasa de ocupación } & \multicolumn{2}{c|}{ Tasa de desempleo } \\
\cline { 2 - 5 } & Hombres & Mujeres & Hombres & Mujeres \\
\hline 2007 & 74,4 & 45,0 & 8,2 & 3,7 \\
\hline 2008 & 75,3 & 45,6 & 7,5 & 3,6 \\
\hline 2009 & 73,7 & 45,2 & 9,0 & 4,9 \\
\hline 2010 & 74,1 & 44,8 & 8,4 & 5,1 \\
\hline
\end{tabular}

Fuente: Elaboración propia a partir de la EHPM

\subsection{Combinación entre trabajo remunerado y no remunerado}

Los indicadores señalan una clara distribución de género entre el trabajo no remunerado y el remunerado, en el primero las mujeres tienen una participación mayoritaria y el segundo los hombres; no obstante, cuando las mujeres ingresan al trabajo remunerado no necesariamente se liberan del trabajo no remunerado como lo han evidenciado las encuestas de uso del tiempo o se ven obligadas combinar ambos trabajos.

Los datos afirman que las mujeres son las que más combinan ambos trabajos o que se ven obligadas a tener una jornada laboral menor en el trabajo remunerado a fin de disponer de tiempo para el trabajo en el hogar; en 2009 el 14,4\% de las mujeres ocupadas indican que tienen una jornada menor a 40 horas debido a motivos de quehaceres domésticos y razones familiares, en tanto que sólo el $1 \%$ de los hombres exponen ese motivo (Gráfico 4); por otra parte, ese mismo motivo es una de las causas importantes por la que a veces tienen que abandonar el trabajo remunerado. ${ }^{19}$

19. En 2009, el 8.6\% de la mujeres desocupadas exponen como motivo de su situación o de abandono de su trabajo el hecho que debía realizar tareas del hogar, porcentaje que para los hombres es del $0.7 \%$. 
Gráfico 4

Población ocupada con jornada menor a 40 horas a la semana según motivos, 2009

(Porcentaje)

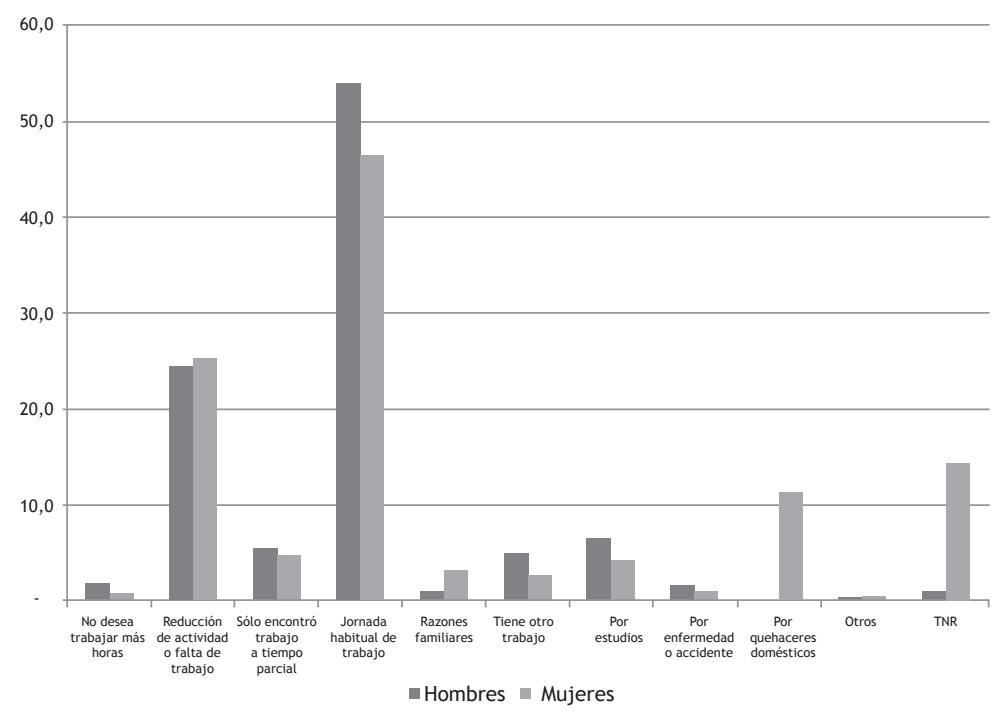

Fuente: Cálculos propios a partir de la EHPM

\subsection{Empleo precario}

Uno de los mayores problemas que presenta el mercado de trabajo salvadoreño es el empleo precario caracterizado por el subempleo y la informalidad, en donde la participación de las mujeres es mayor con respecto a los hombres. El subempleo se define como el porcentaje de población ocupada que trabaja involuntariamente menos de 40 horas a la semana sumada la que trabaja las 40 horas o más pero con ingresos menores al salario mínimo establecido, las mujeres que tienen ese estatus laboral representan el $33.4 \%$ de las ocupadas y los hombres el $31.2 \%$ en el área urbana.

Asimismo, más de la mitad de las mujeres ocupadas están en el sector informal ${ }^{20}$ (Gráfico 5), que por lo general está integrado por pequeñas unidades productivas con baja productividad y tecnología, en donde las garantías de las prestaciones sociales son menores y la incidencia de la pobreza en la población trabajadora es mayor.

20. Según el sistema de estadísticas, el sector informal es aquel segmento del mercado de trabajo compuesto por: asalariados y trabajadores familiares ocupados en establecimientos de menos de cinco trabajadores; y, trabajadores por cuenta propia y patronos de empresas con menos de cinco trabajadores en ocupaciones no profesionales, técnicas, gerenciales o administrativos (DIGESTYC, 2010). 


\subsection{Actividad económica}

Como se puede ver en el gráfico 6, en cierta medida la distribución de mujeres y hombres en las diferentes actividades económicas está determinada por el orden de género, las mujeres participan más en aquel sector que es una extensión de los roles que tradicionalmente son asignados a las mujeres en la esfera del hogar: servicios comunales, enseñanza y hogares con servicios domésticos, en el caso de la industria manufacturera su explicación se encuentra debido al peso de la maquila textil/confección y comercio porque es un sector que facilita a muchas mujeres combinar el trabajo del hogar con la obtención del ingreso y en donde a mayoría de las mujeres están en calidad de cuenta propia. Por su parte, los hombres se encuentran en actividades masculinizadas como agricultura, industria, construcción, transporte, intermediación financiera y administración pública.

\section{Gráfico 5}

Población ocupada en situación de subempleo y en sector informal (Área urbana y porcentaje)

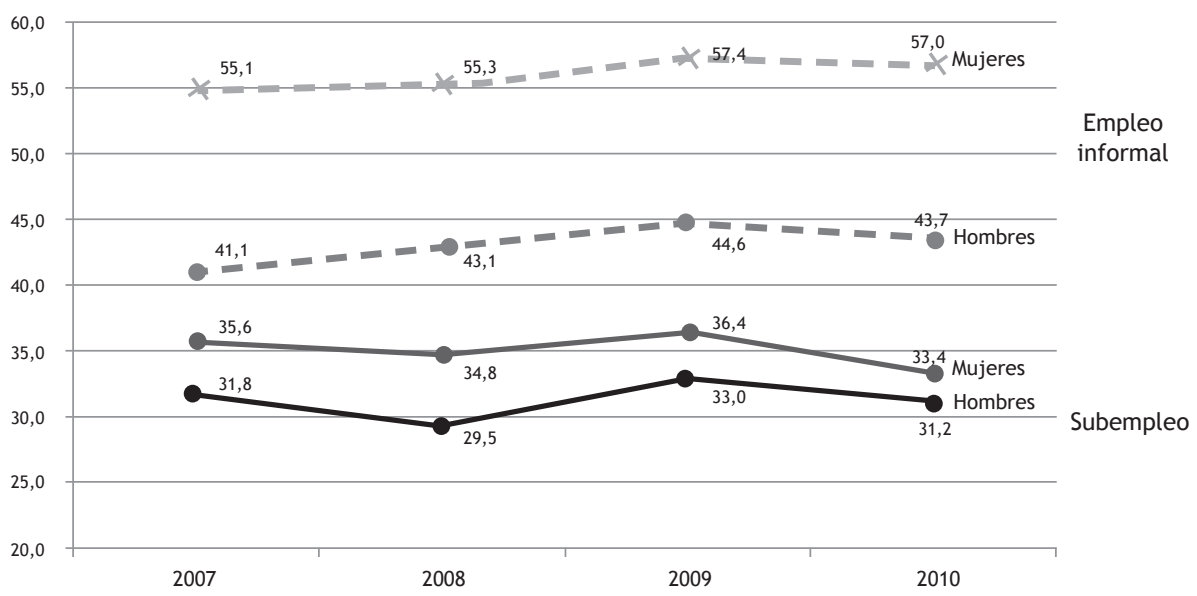

Fuente: Elaboración propia a partir de la EHPM 
Gráfico 6

Población ocupada según rama de actividad económica, 2010

(Porcentaje)

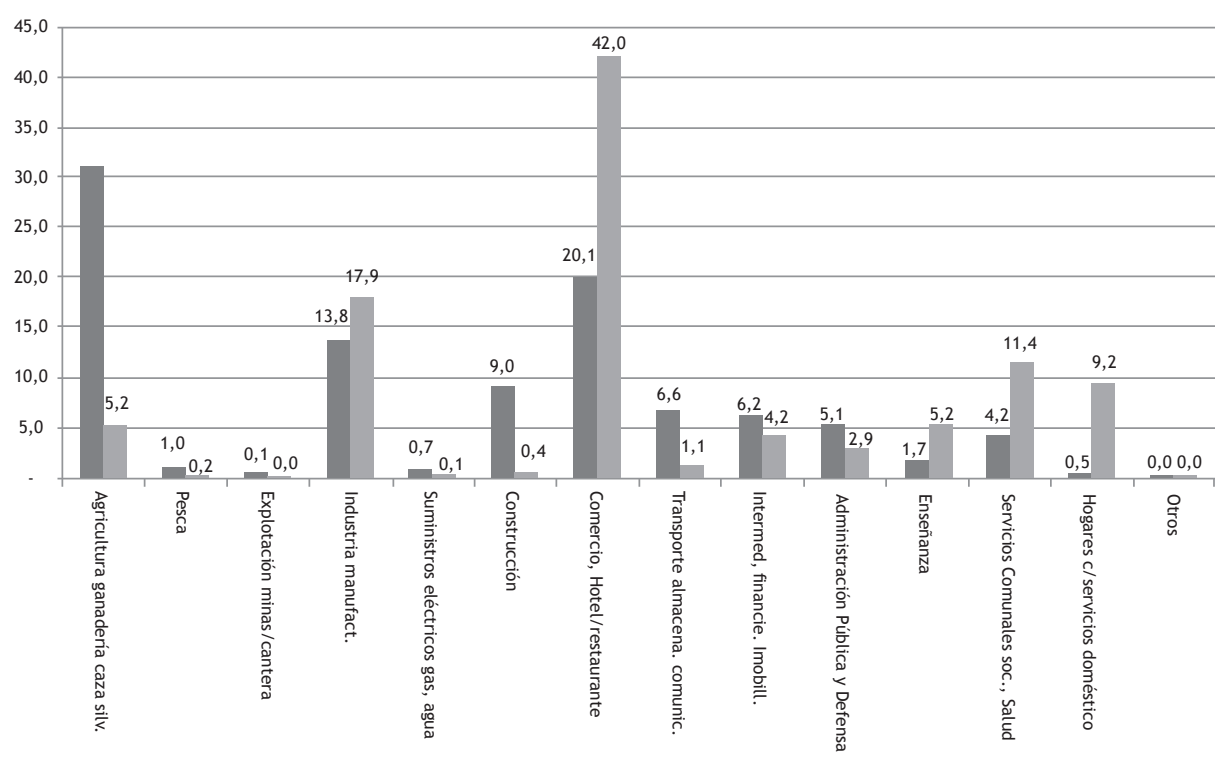

Hombres Mujeres

Fuente: Elaboración propia a partir de la EHPM

Otro dato a destacar, es la distribución de la población según categoría ocupacional (Gráfico 7), más de la mitad de hombres y mujeres trabajan en calidad de cuenta propia y como asalariados permanentes pero la brecha de género es mucho mayor en la primera, en donde la participación de las mujeres despunta con respecto a la de los hombres, en tanto que estos sobresalen como asalariados. El cuentapropista se caracteriza por sus altos niveles de informalidad y baja seguridad social de la población trabajadora, en 2010, el $\mathbf{9 3 . 7 \%}$ de la población ocupada urbana en cuenta propia está en el sector informal y el $88 \%$ no está cubierta por las la seguridad social o ISSS. 
Gráfico 7

Población ocupada según categoría, 2010

(Porcentaje)

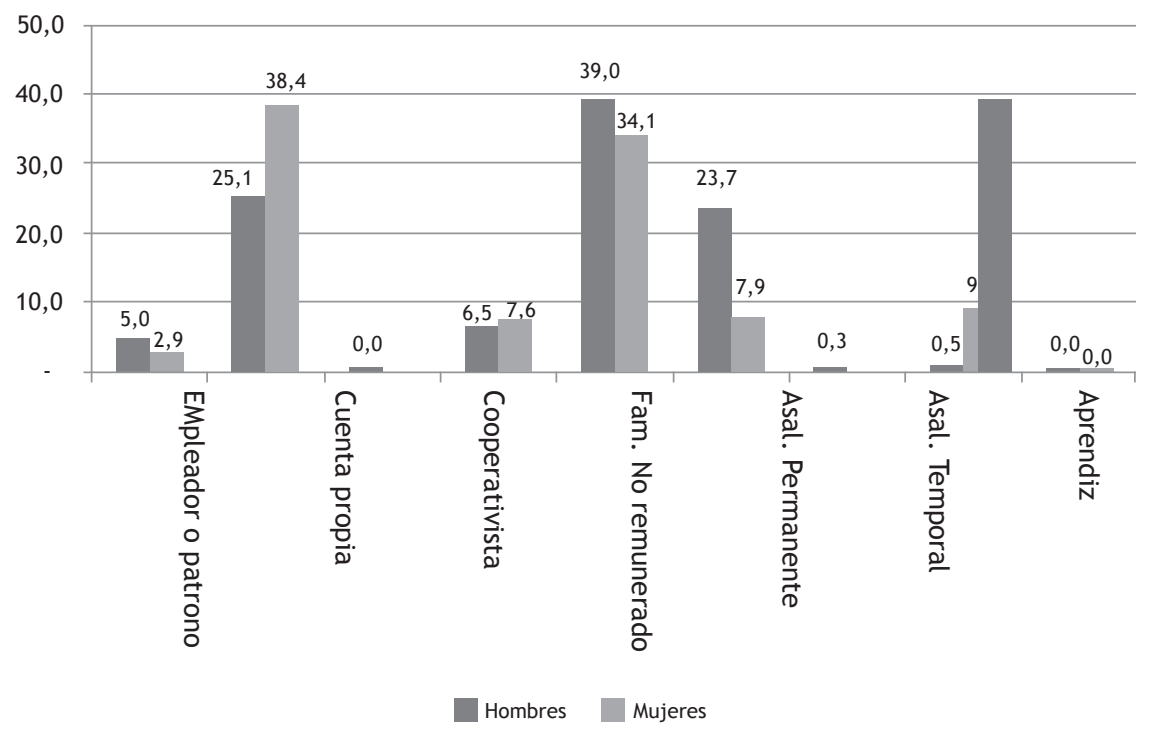

Fuente: Elaboración propia a partir de la EHPM

\subsection{Ejercicio del poder y acceso a la propiedad de las empresas}

El orden de género asigna a los hombres el rol de ser los portadores de poder y del ejercicio de la autoridad, esta norma de género es reproducida en el mercado de trabajo cuando se observa que la participación de los hombres en la propiedad de las empresas y en las funciones de dirección es mayor con respecto a las mujeres; el $5 \%$ de los hombres ocupados trabajan en calidad de empleadores y/o poseen uno o varias empresas, mientras que sólo el 2.9\% de las mujeres están en dicha categoría ocupacional (Gráfico 7). Además, la distribución según sexo de la población dentro de la mismas categoría nos indica que del total de personas empleadores o patrono el 70,1\% son hombres y el 29,9\% mujeres (Gráfico 8), el mismo comportamiento de los indicadores se observa para el grupo ocupacional de dirección y funcionariado. 


\section{Gráfico 8}

Población ocupada en calidad de empleadora/patrono y en grupo ocupacional de dirección/funcionariado, 2010

(Porcentajes)

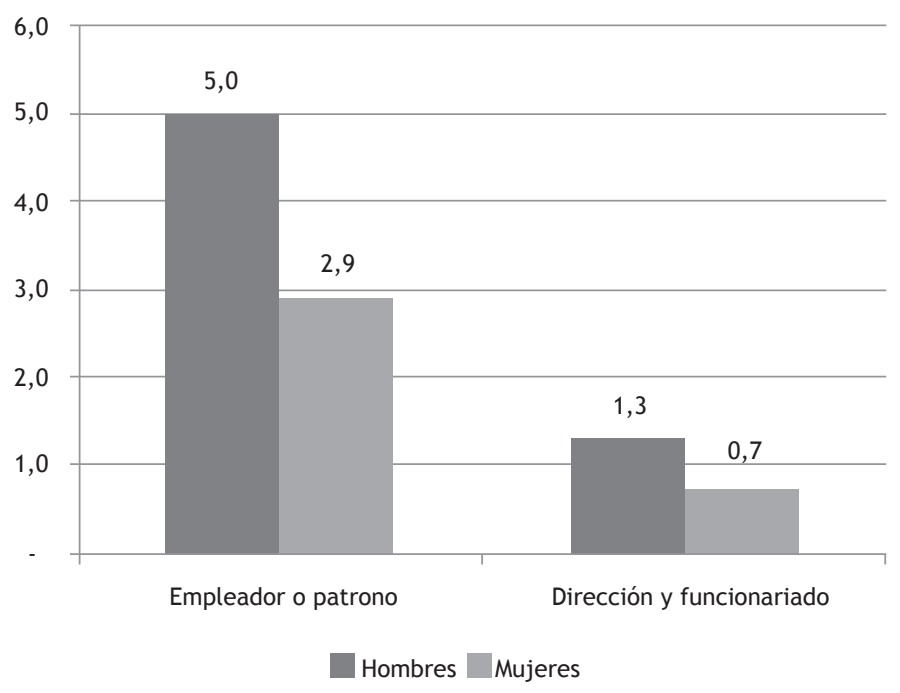

Fuente: Elaboración propia a partir de la EHPM

\section{Gráfico 9}

Empleadora/patrono y grupo ocupacional de dirección/ funcionariado según sexo, 2010

(Porcentajes)

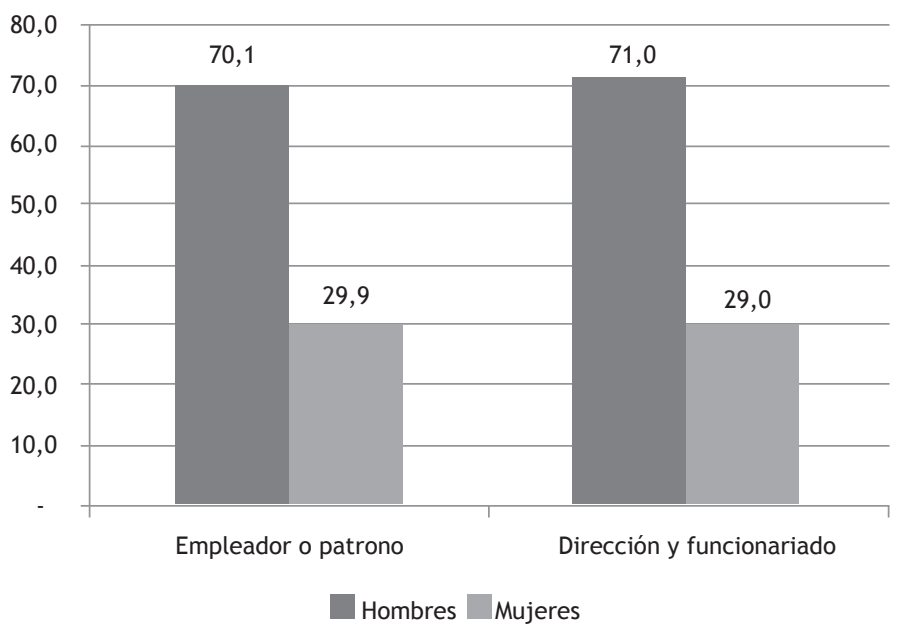

Fuente: Elaboración propia a partir de la EHPM 


\subsection{Salarios}

El orden de género se caracteriza por la desvalorización de lo femenino y la sobrevaloración de lo masculino, ello ha repercutido en que el trabajo que realizan las mujeres tiende a tener un menor valor que el realizado por los hombres dando lugar a brechas salariales en actividades o trabajos de igual valor; los hombres ganan un $\mathbf{1 5 . 5 \%}$ más que la mujeres (gráfico 9), en uno de los grupos ocupacionales mejor remunerados y en donde el trabajo es de igual valor para ambos sexos: dirección y funcionariado, los hombres ganan $9.1 \%$ más que las mujeres.

Desde el orden de género se supone que las mujeres tienen capacidades "innatas" para realizar el trabajo doméstico, esto implicaría que las mujeres tienen una ventaja comparativa con respecto a los hombres, serían mucho más productivas por lo que consecuentemente su salario debería ser mayor; sin embargo, los hombres que se dedican al servicio o trabajo doméstico remunerado ganan un $30.7 \%$ más que las mujeres, lo cual es constante que todo trabajo realizado por los hombres tiene mucho más valor aún en aquellas actividades "propias" de las mujeres.

\section{Gráfico 10}

Salarios y brecha salarial de género según categoría ocupacional, 2010

(US\$ y porcentaje)

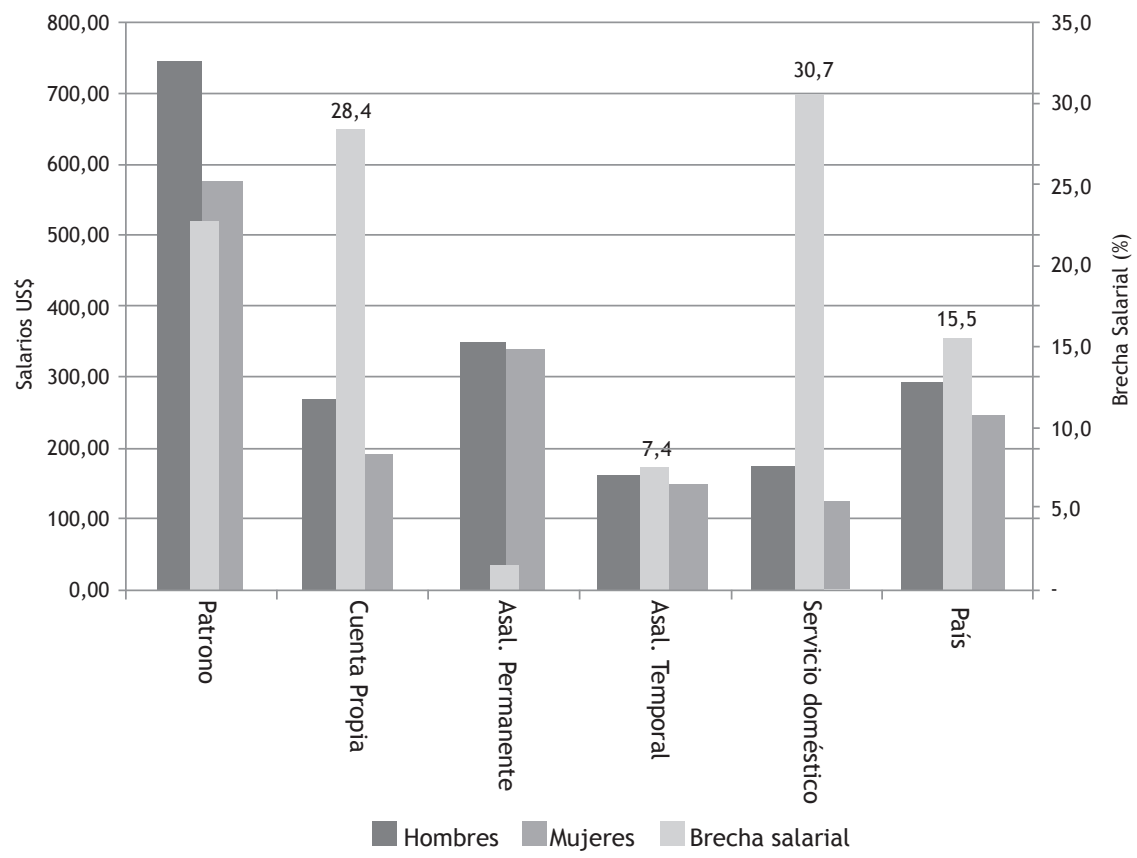

Fuente: Elaboración propia a partir de la EHPM 


\subsection{Estabilidad laboral}

La estabilidad laboral se puede definir como el tiempo de duración de un acuerdo entre una persona trabajadora y su empleadora, por lo tanto la ausencia de un contrato de trabajo conduce a acentuar la incertidumbre en el trabajo, colocando a las personas en una situación de menor seguridad social y jurídica, ya que este otorga una garantía adicional de los derechos laborales, protección contra despidos injustificados y abusos por parte del contratante.

En el sector privado, sólo el 19,2\% de la población ocupada dispone o ha firmado un contrato de trabajo (Gráfica 10), lo que estaría indicando la disponibilidad de una fuerza de trabajo vulnerable y flexible al despido injustificado, los hombres que han firmado contrato superan en 4,4 puntos a las mujeres, estas superan significativamente a los hombres en cuanto a que no tienen certeza de su estatus contractual, ya que el $60.3 \%$ de las mujeres ocupadas no sabe o no responde al respecto sobre su estado contractual (Gráfico11).

Gráfico 11

Población ocupada en el sector privada que ha firmado contrato de trabajo.

(Porcentajes)

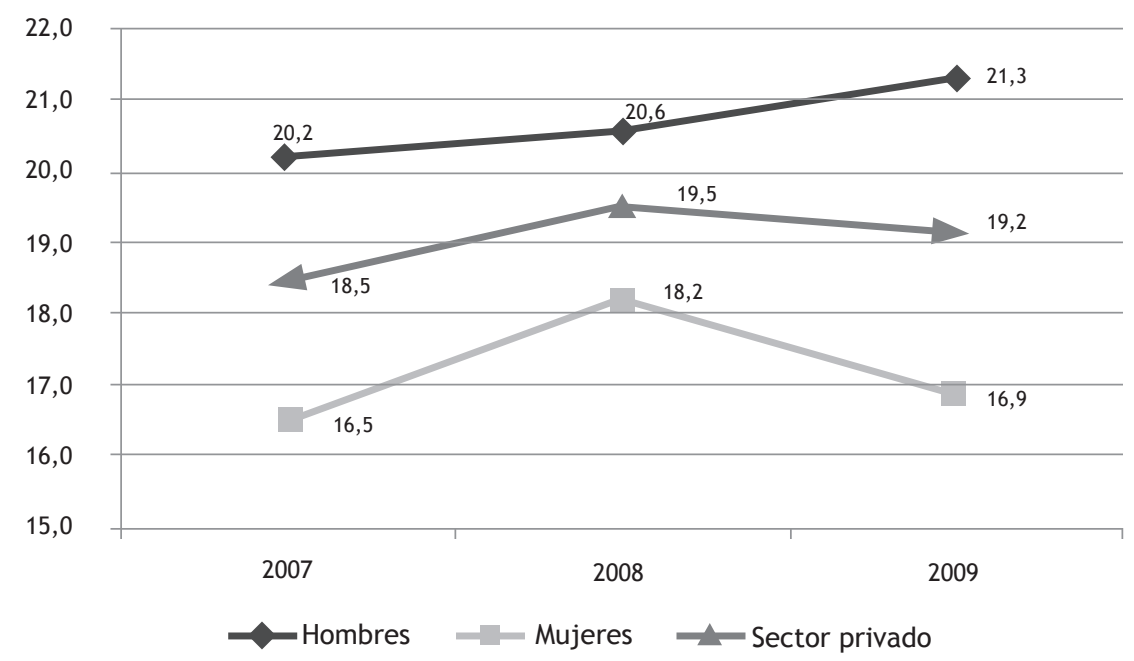

Fuente: Cálculos propios a partir de la EHPM 
Gráfico 12

Estatus contractual de la población ocupada en el sector privado, 2009

(Porcentajes)

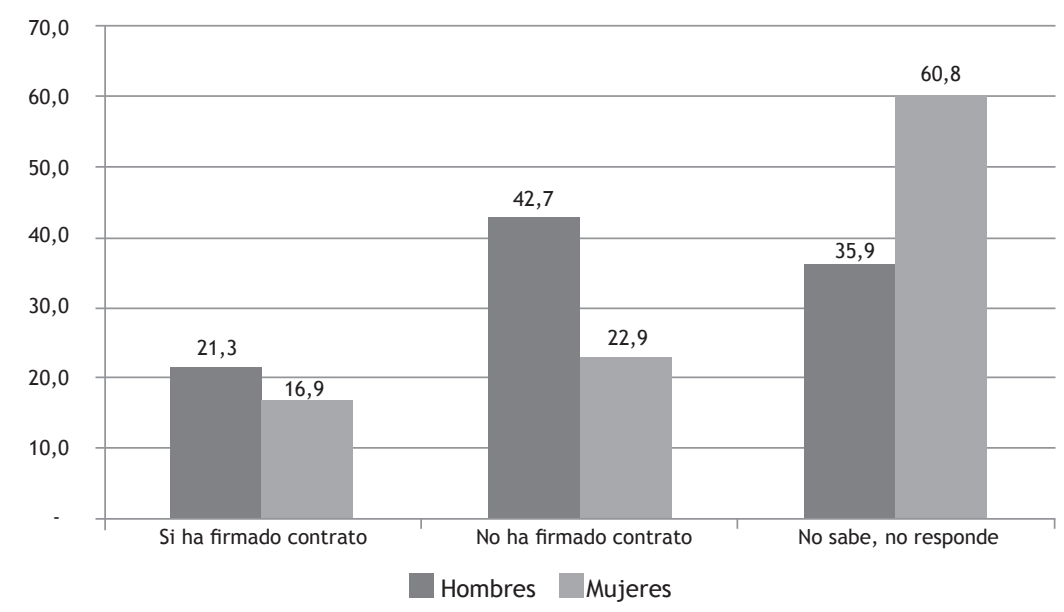

Fuente: Cálculos propios a partir de la EHPM

\subsection{Seguridad social}

Las prestaciones de la seguridad social constituyen un derecho importante para garantizar la salud y productividad de la fuerza de trabajo, asimismo aseguran un retiro digno a las personas después de su permanencia en el mercado de trabajo; dos indicadores -cobertura del ISSS y la densidad de cotización- nos aproximan al estado de protección social de la fuerza de trabajo.

En los últimos años los niveles de protección social han venido cayendo lentamente, en 2006 el 46,2\% de la población ocupada en el área urbana no está cubierta por las prestaciones del ISSS, para 2010 el valor del indicador es del $54.1 \%$, la caída ha afectado especialmente a las mujeres aunque estas mantienen una cobertura mayor en relación a los hombres (Gráfico 12), no obstante, cabe preguntarse cuántas de estas mujeres están en calidad de beneficiarias y cuántas en calidad de contribuyentes directo.

En lo referente al derecho a la contribución de la fuerza de trabajo para disponer de una pensión de jubilación luego de su permanencia en el mercado de trabajo, los datos no son del todo alentadores. A 2010, el 91,6\% de la población ocupada está afiliada a las Administradoras de Fondo de Pensiones AFP-, sin embargo, sólo el $28 \%$ de las personas afiliadas cotizan efectivamente a las administradoras -densidad de cotización- o están asegurando un retiro digno del mercado de trabajo, la tendencia en los últimos años ha sido hacia la baja como se puede ver en el gráfico 13 , afectando especialmente a las mujeres. 


\section{Gráfico 13}

Población ocupada cubierta por el ISSS en el área urbana, 2010

(Porcentajes, área urbana)

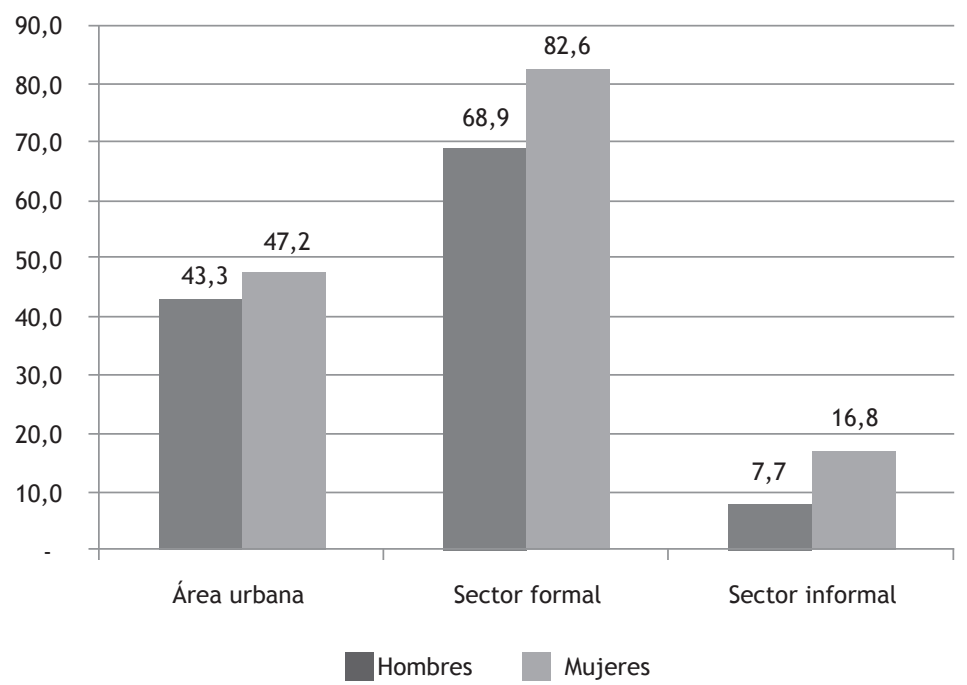

Fuente: Elaboración propia a partir de la EHPM

Gráfico 14

Población afiliada a las AFP que cotizan al fondo de pensión

(Porcentajes)

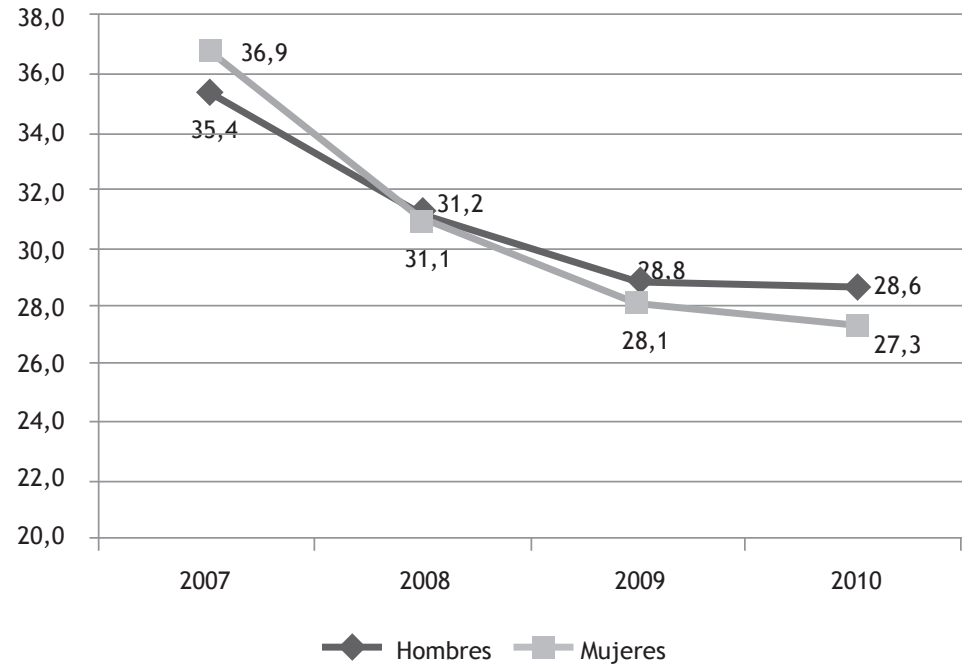

Fuente: Elaboración propia a partir de la EHPM 


\subsection{Sindicalización}

El sindicalismo juega una labor importante en cuanto a que es un espacio de contrapeso a los intereses del capital y para la reivindicaciones de los derechos de la fuerza de trabajo. Asegurar que las acciones de incidencia política no estén marcadas por un sesgo de género pasa por promover una participación paritaria dentro del mismo así como asegurar un pleno reconocimiento de las mujeres como interlocutor válido.

Es importante señalar que El Salvador tiene una baja cultura sindical, sólo el $11,3 \%$ de los ocupados en calidad de asalariados forman parte de alguna organización sindical; por otra parte, es un espacio masculinizado, la tasa de los hombres es de $13,6 \%$ en tanto que la de las mujeres es de 6,5\%; del total de personas afiliadas a los sindicatos el $81,1 \%$ son hombres y el $18,9 \%$ mujeres (Gráfico 14 y 15).

La baja participación de las mujeres en los sindicatos, así como el hecho de que la mayoría de los contratos colectivos pertenecen a ramas de actividad económica masculinizadas ha repercutido en que sólo un bajo porcentaje -3,2\%de mujeres asalariadas estén cubiertas por los contratos colectivos, la tasa de los hombres es del 5,5\%, aunque la tasa de cobertura ${ }^{21}$ en términos generales es muy baja en el país -4,5\%-.

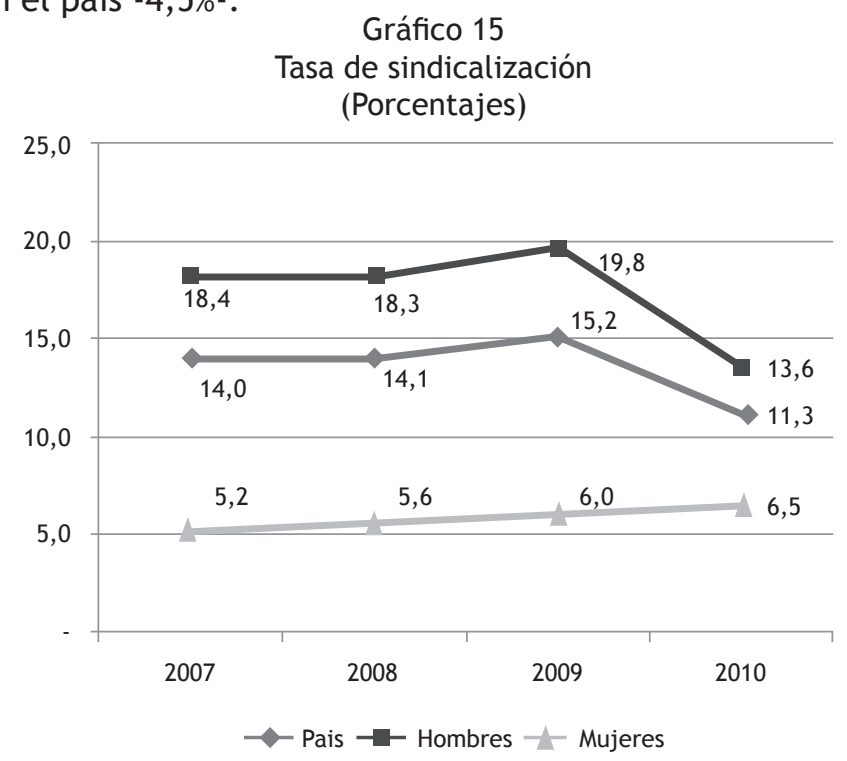

Fuente: Ministerio de Trabajo y Previsión Social. 
Gráfico 16

Población afiliada a los sindicatos según sexo, 2010

(Porcentajes)

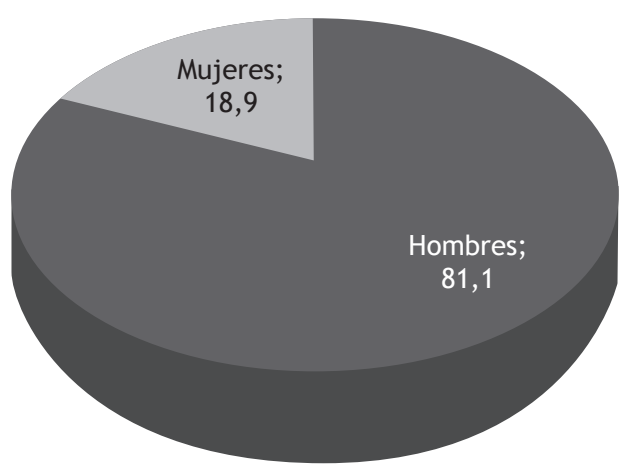

Fuente: Elaboración propia a partir de datos del MTPS

3.9 Visión de conjunto de las desigualdades de género

El gráfico 16 proporciona una visión de conjunto de las brechas de género en cada uno de los componentes que se han analizado del mercado de trabajo; las brechas se han indexado a través de un proceso de normalización, ${ }^{22}$ cada índice de brecha toma valores entre 0 y 1 , en donde un valor próximo a 1 -círculo celeste del gráfico- reflejaría que hombres y mujeres se acercan a la igualdad de género en el componente del mercado de trabajo en cuestión, un valor cercano a 0 -centro del gráfico- indica una situación de mayor presencia de desigualdades de género.

22. La metodología para la elaboración de los índices consiste en calcular las brechas de género de cada indicador, luego se procede a la normalización de las mismas utilizando la formula siguiente:

Donde:

$$
I N O R y=\frac{\mathrm{Xij} \operatorname{minXij}}{\max X \mathrm{ij}-\min X \mathrm{ij}}
$$

INORij = Brecha de género normalizado del indicador i y perteneciente al área $\mathrm{j}$

$\mathrm{Xij}$ = Valor de la brecha real del indicador $\mathrm{i}$ del área $\mathrm{j}$, por lo general expresado en porcentajes MinXij =Valor mínimo de la brecha de género del indicador i del área $j$

Max Xij = Valor máximo de la brecha de género del indicador i del área j (por lo general la meta o nivel a que se desea llegar)

De acuerdo a la formula, aparte del valor real del indicador a habrá que asignarle valores máximo y mínimos, que en cierta forma puede representar los limites deseados o permitidos en los cuales se puede mover el valor del indicador, el valor máximo puede representar la meta a la que se desea llegar y valor mínimo la situación más desfavorable en la que se puede encontrar el valor del indicador, aunque esto dependerá de la interpretación de lo que busca representar el indicador. Para los propósitos de este estudio, el valor máximo asignado a la brecha de género de cada indicador es de "0"y el valor mínimo es de "100". Esto es así ya que, el objetivo máximo para lograr la igualdad es que la brecha de género se reduzca a un $0 \%$, por lo que Max Xij = 0; y el valor mínimo representa la brecha más alta a la que se puede llegar, un 100\%, situación de plena desigualdad. 
Como se observa, los componentes de trabajo no remunerado y combinación del trabajo remunerado con el no remunerado presentan brechas de género significativamente altas, como lo señalaron los indicadores anteriores las mujeres son las que mayoritariamente cargan con el trabajo no remunerado y las que más reducen su jornada laboral remunerada para dedicarle tiempo al trabajo del hogar; mientras que seguro social y pensiones se acercan a la igualdad, es decir, que presentan una mínima brecha o tanto hombres como mujeres tienen porcentajes similares de cobertura de la seguridad social como de densidad de cotización, pero el problema reside en que el acceso de la fuerza de trabajo a las prestaciones del ISSS y las pensiones es muy bajo.

\section{Gráfico $17^{23}$}

Visión de conjunto de las desigualdades de género en el mercado de trabajo, 2010 (Índices de brechas de género)

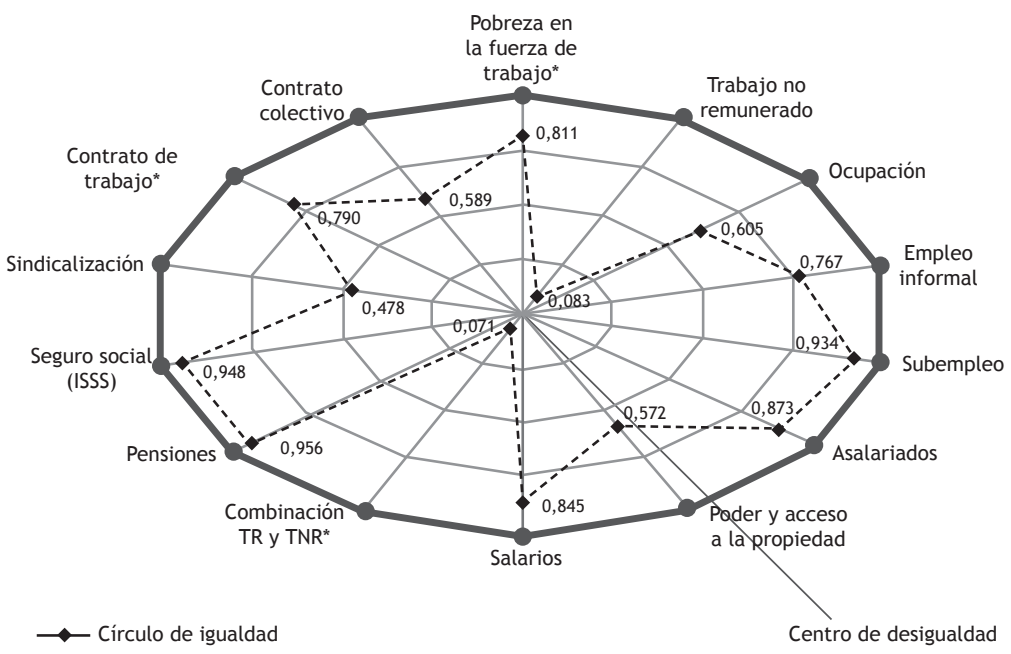

Fuente: Elaboración propia a partir del datos del MTPS, SIP y la EHPM.

\footnotetext{
23 Notas:

-Pobreza de la fuerza de trabajo: PET que no reporta ingresos.

Ocupación: tasa de ocupación.

- Trabajo no remunerado: población inactiva en quehaceres domésticos y obligaciones familiares.

-Empleo informal: población ocupada en el sector informal, área urbana

-Subempleo, población ocupada en situación de subempleo, área urbana.

- Asalariado, población ocupada en calidad de asalariados permanentes.

- Poder y acceso a la propiedad, promedio de los indicadores sobre ocupados en calidad de empleadores y dirección

-Salario: brecha salarial

- Combinación entre trabajo no remunerado y remunerado: población ocupada con jornada menor a 40 horas a la semana por motivos de quehaceres domésticos y razones familiares.

-Pensiones: densidad de cotización

-Seguro social: personas ocupadas cubiertas por el ISSS, área urbana.

-Sindicalización: tasa de sindicalización

- Contrato de trabajo, personas en el sector privado que han firmado contrato.

- Contrato colectivo: tasa de cobertura de los contratos colectivos.
} 
En la mayor parte de los componentes, los hombres tienen una posición superior en relación a las mujeres ya que las brechas de género son favorables a ellos. La mujeres tienen una posición superior en aquellos componentes del mercado de trabajo en donde las condiciones de trabajo y sociales no son satisfactorias -excepto seguridad social-, así la participación de las mujeres es mayor con respecto a los hombres en subempleo, empleo informal, trabajo no remunerado y combinación de trabajo remunerado con el no remunerado.

\section{Consideraciones finales}

La reflexión sobre la noción de género que se presenta en la primera parte ha pretendido aportar elementos que permitan superar y romper la visión binaria del género dentro del estudio de la economía, especialmente en el mercado de trabajo en donde las desigualdades de género son mucho más evidentes; no todas las personas comparten una misma identidad genérica. Dicha situación también pone en duda que las características del sujeto económico sean universales o que la formas de concebirnos como sujeto económico sean iguales; sin embargo, el sujeto económico está reglamentado según el orden de género. Por consiguiente, juega una función de inteligibilidad de lo humano y esa reglamentación nos hace creer y naturalizar que existe una forma única de ser sujeto económico, de acceder al poder o a los recursos económicos, lo que implica que para ser persona en la economía es necesario revestirse de una determinada identidad de género -no necesariamente deseada-, porque de lo contrario se pasa a ser una especie de sujeto económico abyecto o desvalorizado.

La economía como se señaló al inicio es una institución social donde se da y se hace el género, por lo tanto es susceptible de que instaure la matriz de inteligibilidad heterosexual que propone Judith Butler; la matriz es una categoría social desde la cual se organiza la identidad, los cuerpos y lo humano; la heterosexualidad se establece como régimen de poder y reglamentación de sujeto (Butler, 2007) indicando quiénes son persona, qué cuerpo y sexualidad importa y cuáles son abyectas. Ahora bien, ¿están exentas las personas como sujeto económico de la matriz? ¿Hasta qué punto la matriz define, condiciona lo que significa ser sujeto económico? ¿La matriz en la economía convierte en abyecta a las mujeres heterosexuales? ¿La matriz conduce a los abyectos a la renuncia de su identidad para ser reconocidos como sujetos económicos o a caer en una especie de travestismo identitario?

Los progresos en materia de igualdad de género en el marco institucional y legal entre 2009 y 2011 son un hito en la historia reciente de El Salvador; con la finalización de la guerra civil en 1992, el país realizó esfuerzos importante en cuanto a la promoción y garantía de los derechos humanos; sin embargo, a las acciones del Estado para lograr un entorno favorables para la igualdad 
de género no tuvieron un peso importante dentro de las políticas públicas, el acentuado interés por implementar las políticas de ajuste y la estabilización económica opacó a la política social.

Con la llegada del partido FMLN al órgano ejecutivo y bajo la presidencia de Mauricio Funes en 2009, las políticas de igualdad se posicionan dentro de la gestión estatal; sin embargo, los marcos interpretativos del documento rector de la política del gobierno nos señalan aspectos interesantes que podrían orientar mucho mejor la definición de la política de igualdad. Por otra parte, merece profundizar hasta qué medida hay un compromiso serio por parte del Estado para generar acciones que debiliten el poder de determinados actores sociales en las decisiones que les conciernen a las mujeres, así como asegurar el reconocimiento y representación de las mujeres y de las otras identidades de género como interlocutoras válidas en la vida económica, política y social.

La pertinencia de las políticas públicas en la igualdad de género pasa por reflexionar quién o quiénes cuentan como sujetos de justicia, así como entender que la justicia no se reduce al plano de la redistribución económica. Nancy Fraser entiende la justicia como paridad participativa entre los miembros de la sociedad y que la raíz de la injusticia no sólo es un problema de redistribución de los recursos sino también de falta de reconocimiento y representación (Fraser, 2008); es decir, que la paridad de participación de los géneros en la economía no se resuelve sólo con el acceso equitativo entre los géneros a los recursos económicos o por una justa distribución de la falta de ingreso. La falta de reconocimiento de los géneros como sujeto económico, así como la falta de representación política de los mismos como interlocutores válidos y voz propia en la economía puede generar que los esfuerzos de redistribución vengan marcados con un sesgo de género.

Es constante el peso que tiene el orden de género en el mercado de trabajo. La división de trabajo se presenta como un principio vigente y regulador de los espacios que hombres y mujeres asumen en la esfera privada y pública; los indicadores señalan que las mujeres tienen mayores niveles de pobreza, asumen una carga mayor del trabajo no remunerado, sufren de discriminación salarial, presentan una mayor incidencia en el empleo precario, menor cobertura de la seguridad social - también los hombres-, menor estabilidad laboral y participación en las estructuras organizativas del mercado de trabajo.

Queda por extender este análisis a los otros géneros ya que cada uno tendrá sus particularidades en cuanto al estilo de inserción al mercado de trabajo y el efecto regulador de este en la identidad de género. Asimismo, resultaría interesante una aproximación al estado de las dimensiones de la justicia que plantea Fraser en la economía, si bien los indicadores proporcionan una idea en cuanto a la justicia redistributiva porque las personas sufren falta de 
reconocimiento y representación en la economía, y es que esta como institución social y productora de la matriz de inteligibilidad heterosexual tiene que ver mucho con esas dos dimensiones de la justicia, que muy pocas veces son consideradas en los análisis e impacto de la política económica.

\section{Bibliografía}

Badgett, Lee y Folbre, Nancy (1999). “¿Quién cuida de los demás? Normas socioculturales y consecuencias económicas”. Revista Internacional del Trabajo, vol. 118, núm. 3, pp. 348-365, 1999

Butler, Judith. Deshacer el género, Piadós. Barcelona 2006

Butler, Judith. El género en disputa. El feminismo y la subversión de la identidad. Piadós. Barcelona 2007

Bustelo, María y Lombardo, Emanuela -Eds-. Políticas de igualdad en España y en Europa. Ediciones Cátedra. Madrid 2007

Çagatay, Nilüfer (2004). “Incorporación de género en la macroeconomía”. En: An Anthology: Local Human Development. Universidad de la Habana, Cuba. http://hdrnet.org/206/ Consultado el 14 de marzo 2011.

Çagatay, Nilüfer. “El comercio, el género y la pobreza. Programa de las Naciones Unidas para el Desarrollo”, 2003

http://www.undp.org.cu/pdhl/Modulo4/use/tema3/doc15.pdf Consultado el 21 de febrero 2011.

Carrasco, Cristina. "Mujeres, sostenibilidad y deuda social”. Revista de Educación, número extraordinario 2009, pp. 169-191, 2009

Chihu, Aquiles. "Marcos interpretativos, identidad e imaginario en el mexica movement. Religión y Sociedad”, Vol. XIX, No. 38. México 2007.

Coll-Planas, Gerad. La voluntad y el deseo. La construcción social del género y la sexualidad: el caso de lesbianas, gays y trans. Egales. Barcelona 2010.

Espino, Alma. “Economía feminista: enfoques y propuestas”. Serie Documentos de Trabajo DT 5/10. Instituto de Economía 2010.

http: / / www.iecon.ccee.edu.uy/publicaciones / AEspino\%20DT-5-10.pdf

Consultado el 16 de junio de 2011 
Fracer, Nancy. Escala de Justicia. Herder Editorial. España 2008.

Gálvez, Lina y Torres, Juan. Desiguales. Mujeres y hombres en la crisis financiera. Icaria editorial. Barcelona 2010.

Gil de San Vicente, Iñaki. "Capitalismo y emancipación nacional y social de género”. 1a edición electrónica en Internet por la Red Vasca Roja el 4/01/2001. http://www.rebelion.org/mujer.htm Consultado el 23 de marzo 2010, 2000

GOES. Plan Quinquenal de Desarrollo. Gobierno de El Salvador. San Salvador 2010.

Hlupekile Longwe, Sara. ¿Es posible un mundo sin discriminación? Ponencia presentada en el seminario: Feminismos globales, diversos y plurales. Foro Social Mundial. Porto Alegre. http://alainet.org/publica/ retosfem/posible.html 2002.

ISDEMU. Política nacional de las mujeres. San Salvador 2011.

Lamas, Marta.Cuerpo: diferencia sexual y género. Taurus Pensamiento. México 2002

Martín Casares, Aurelia Antropología del género: culturas, mitos y estereotipos sexuales, Ediciones Cátedra, Universidad de Valencia 2006

Scott, Joan. “El género: una categoría útil para el análisis histórico”. En Historia y género: las mujeres en la Europa moderna y contemporánea, James y Amelang y Mary Nash (eds.), Edicions Alfons el Magnanim, Institució Valencina d Estudis i Investigació. Este artículo fue publicado en Inglés como "Gender: A Useful Category of Historical Analysis" en American Historical review, 91,1986, pp. 1053-1075, 1990

SIS. Ciudad Mujer. Secretaria de Inclusión Social.

http: / / www.ciudadmujer.gob.sv/images/docs/Ciudad\%20Mujer\%20El\%20 Salvador.pdf Consultado el 2 de febrero de 2012.

Leyes y decretos

Decreto Ejecutivo No 74 "Reglamento de creación y aplicación del régimen especial de salud y maternidad para los trabajadores domésticos". Diario Oficial. Tomo No. 387. Miércoles 12 de mayo 2010. San Salvador. 
Decreto Ejecutivo No 74 "Reglamento de creación y aplicación del régimen especial de salud y maternidad para los trabajadores domésticos". Diario Oficial. Tomo No. 387. Martes 1 de junio 2010. San Salvador.

Decreto No. 645 "Ley de Igualdad, Equidad y Erradicación de la Discriminación Contra las Mujeres". Disponible en http://www.isdemu.gob.sv/index. php?option=com_phocadownload\&view=category\&id=17\%3Alegislacion \&ltemid=234\&lang=es 
